\title{
THE COLLABORATIVE PROGRAM OF RESEARCH IN ENGINEERING SCIENCES
}

\author{
September 1, 1988 to August 31, 1989
}

\section{DISCLAIMER}

\begin{abstract}
This report was prepared as an awownt of work sponsored by an agency of the United States Thia report was prepared as an acse Government nor any agency thesoof, nor any of their Government. Neither the United States Government nor ans impliod, or assumes any legal liability or responsiemployes, makes any warranly, express or isefulness of any information, apparatus, product, or

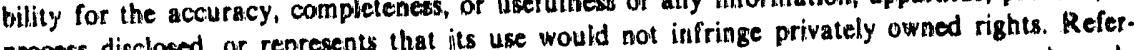
process disclosed, or represents that its use would not in ringe privately owned rights. Reference herein to any specific commercial product, proxess, or service by imply its endorsement, recommanufacturer, of otherwise does not necessanily constitute or imply its endorsent, The views mendation, of favoring by the United States Government or any agency thereof. The views and opinions of authors expressed herein do not

United States Government of any agency theroof.
\end{abstract}

Energy Laboratory of the

Massachusetts Institute of Technology

in collaboration with the

Idaho National Engineering Laboratory

August 1989

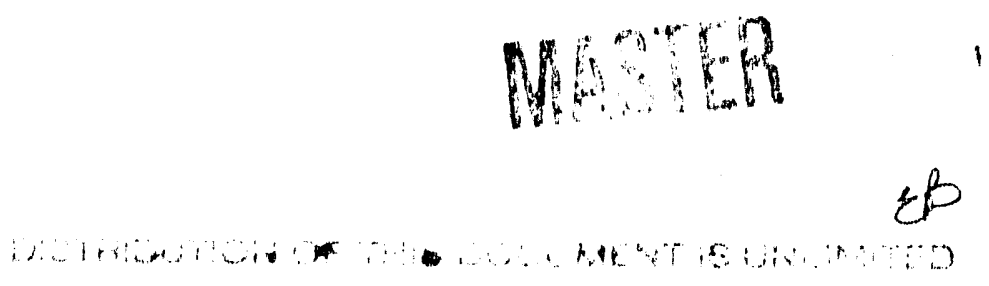




\section{TABLE OF CONTENTS}

INTRODUCTION $\ldots \ldots \ldots \ldots \ldots \ldots \ldots \ldots \ldots \ldots \ldots \ldots \ldots \ldots, \ldots \ldots \ldots$

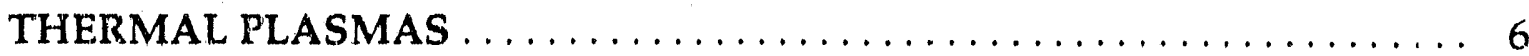

Study of High-Temperature Gas-Particle Reactions ........... 7

Mathematical Modelling of Plasma Systems ............... 16

AUTOMATED WELDING .............................. 19

Metal Transfer in Gas Metal Arc Welding ................ 20

Multivariable Control of Gas-Metal Arc-Welding . ........... 23

ENGINEERING ANALYSIS $\ldots \ldots \ldots \ldots \ldots \ldots \ldots \ldots \ldots \ldots \ldots$

Synthesis of Heat and Work Integration Systems for

Chemirnl Process Plants .............................. 28

Parity Simulation of Dyinamic Processes . . . . . . . . . . . . . . 31

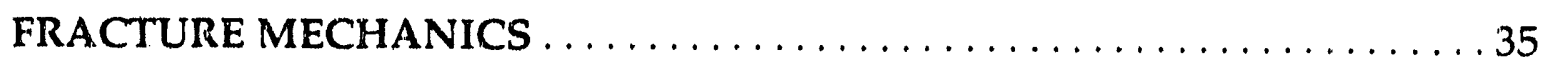

Fundamentals of Elastic-Plastic Fracture:

Three-Dimensional and Mechanistic Modelling . . . . . . . . . 36

Comminution of Energy Materials $\ldots \ldots \ldots \ldots \ldots \ldots \ldots \ldots \ldots, 41$ 


\section{INTRODUCTION}

In 1985, the Energy Laboratory of the Massachusetts Institute of Technology (MIT) and the Idaho National Engineering Laboratory (INEL) began a collaborative program of energyrelated engineering research. Since then, the program has been pursuing three broad goals: to perform quality research on energy-related technologies involved in industrial processes and productivity; to demonstrate the potential of collaborative programs between universities and the national laboratories; and to encourage the transfer of the technology developed to the industrial sector. This annual report describes progress at MIT under the MIT/INEL program during the past year.

\section{Research Progress}

Highlights of research activities and accomplishments during the past year include the following.

\section{Thermal Plasmas}

- We developed techniques that enabled us to more accurately measure the temperatures of particles as they encounter the extreme conditions typical of those in thermal plasma flames, and we extended our experiments to a wider variety of materials than previously studied.

- We refined and validated our mathematical model that predicts temperature, velocity, and concentration profiles in plasma plumes and applied the results to predict the behavior of particles in the flow. We are developing a representation of plasma phenomena inside the torch.

\section{Automated Welding}

- We used imaging techniques developed previously under this program to measure the rate at which the electode melts in gas-metal arc welding (GMAW); and, based on those and other measurements, we developed the most complete model of metal transfer in gas-metal arc welding that is now available.

- We have developed a novel model of the GMAW process dynamics; and based on this and measurement methods jointly developed with INEL, we were able to regulate in real time the maximum width and height of the welding pool formed during GMAW.

\section{Engineering Analysis}

- We finished developing methods of synthesizing heat exchange networks (networks for transferring heat from streams that must be cooled to streams that must be heated) capable of hardding the constraints and nonidealities typical of many chemical processes.

- We used our parity simulation approach (which uses electronic hardware to represent physical systems) to model a two-phase, two-fluid system and concluded that, while the approach can handle such complex systems, cost and testing effort may make it impractical. 
Fracture Mechanics

- We used a new finite element approach to calculate the surface displacement that would occur as a surface-cracked plate is subjected to increasing tensile loads and found that our results agreed closely with measurements made at INEL.

- From a preliminary computer simulation of how particle beds behave and particles fracture during grinding, we are examining a new design that promises more rapid crushing and through-flow of material than achievaible with current grinding devices.

The pages that follow contain more details about the past year's work as well as brief descriptions of plans for the coming year (including a budget for each research area). The first 35 attachments are recent publications resulting from this program. The remaining attachments are other documents referred to in the technical write-ups that follow.

\section{MIT/INEL Interaction}

When the MIT/INEL program was initiated, one key motivation was ta report from the White House Science Council on Federal Laboratories that recommended increased collaboration between national laboratories and major research universities. The MIT/DNEL program continues to demonstrate the benefits of such collaboration. Three examples follow.

- An INEL research team is examining the behavior of materials in plasma spraying experiments under carefully controlled, highly instrumented conditions. At the same time, an MIT team is examining how single particles of the same materials change physically and chemically under the same conditions; and a second MIT team is developing a mathematical model that predicts phenomena in such plasma systems. Both teams of experimentalists are guided by the modeling results as they plan their tests and interpret the results, and the theoretical team uses the experimental measurements to test and verify the model.

- Theoretical work at MIT on GMAW has defined the pulse frequencies that produce the highest rates of melting per unit of current and the optimum mode of metal transfer. Researchers at DNEL are now using that information as they develop their new control system for GMAW. Conversely, the MIT researchers have several times drawn on INEL expertise in video sensing to help them set up GMAW experiments.

- An MIT research team is developing a model designed to predict when structural components containing surface cracks will fracture. Meanwhile, an INEL team is performing detailed experiments to examine how such cracks grow and and change. Cooperation between the two teams has led to preparation of a joint manuscript now under review at a major joumal. 


\section{Technology Transfer}

The program has continued in its efforts to iransfer the technology developed and information generated to potential users in industry. One means of transfer is via the technical advisory committees that meet twice a year to help evaluate and guide the work in each research area. Industrial members on those comnittees serve as natural lirks with organizations that can put the research results into practice. In two instances, evidence of successful technology transfer is clear. Fracture mechanics data developed by MIT and INEL suggested that the standards defined by ASTM for testing of surface cracks may be inadequate; ASTM is now using those data to revise the standards. MIT developed a new tochnique using backlighting and high-speed photography to observe directly both the droplet growing on the welding rod and the changing arc during GMAW; that technique is now being used both by INEI and by other welding laboratories. 


\section{THERMAL PLASMAS}




\section{STUDY OF HIGH-TEMPERATURE GAS-PARTICLE REACTIONS}

PERSONNEL

Faculty:

J.F. Elliott, Departmenll of Materials Science and Engineering

Research Staff:

P. Bolsaitis, Energy Lal’oratory

Graduate Students:

J. Duncan, G. Trapaga, M. Salas

\section{ABSTRACT}

This research program is directed to the stildy of the physical and chemical behavior of individual fine particles for conditions encountered by such particles in plasma spraying and processing of materials. The experimental method involves exposing a single particle to high temperatures for a short time, determining the temperature of the particle in the heating and cooling cycle, and examining the physical and chemical character of the reacted particle. The research of the past year has been directed to obtaining accurate single- and two-color temperatures of the particle during the heating and cooling cycle, implementation of a lowtemperature detection system, and experiments with alumina, silicon carbide, boron, and WC$11 \%$ cobalt particles.

\section{GQALS}

The near-term goals of the project are the study of phase transformations and structures of prototype materials for various conditions of temperature pulsing, particle size, and gaseous atmospheres. Those that have been selected for study include ceramic materials (alumina, zirconia), metals (Al-Ni alloys and aluminum), and carbides (silicon carbide, hard-facing materials, and WC-Co). Some of these materials are also being processed in plasma torch spraying under carefully controlled and highly instrumented conditions in the laboratories at INEL. The combination of data from this investigation, the data base from INEL on plasma spraying, and results of modelling of plasma spraying systems by Professor Szekely's group will provide a much more complete understanding of plasma processing of materials than has been available heretofore.

\section{PROGRESS}

The research conducted during the 1988-89 period has centered on calibration and correction methods to obtain accurate temperature measurements of particles as they are rapidly heated and cooled. Concurrently, experiments with a variety of materials as mentioned above have been carried out. Also, a low-temperature measuring apparatus has been designed and built that is based on IR sensors.

\section{A. Calibration of Temperature Measurements in Pulse Heating}

The capability for measuring accurately the time-temperature profile of a pulse heated particle is required to identify phase transformations in the particle and to quantify the rates of transformation. An instrument has been constructed that simulates radiation signals emitted by particles over a range of temperatures and heating and cooling rates. An 
optical imaging system projects a section of a calibrated tungsten filament onto the radiation signal detector in combination with a high-speed optical chopper. This instrument has been employed to determine gain factors and natural noise levels of individual optical and electronic elements of the sensing circuits, and time-response characteristics of one-and two-color temperature measurements under conditions of pulse heating and cooling.

The dependence of instrumental gain factors on signal intensity, especially for longer wavelength signals, is illustrated in Figure 1. Instrumental gain factors and characteristic response times affect the time response of one- and two-color temperature systems as shown previously (1). Response times for temperature signals in pulse heating and cooling were determined as illustrated in Figures 2 and 3 . The response times for both one- and two-color temperatures in heating were found to be less than $0.1 \mathrm{~ms}$ for heating rates in the range of one million degrees Celsius per second, which is sufficiently fast to measure particle heating rates typical of plasma processing. The one-color temperature response times in rapid cooling, on the other hand, were found to be in the range of $1.05 \mathrm{~ms}$ for equivalent cooling rates, thus requiring significant corrections to relate apparent temperatures to true temperatures. The sensitivity of presently employed instruments and circuitry to differentiate between cooling rates is impaired below approximately ten million degrees per second, and this is faster than most cooling rates measured experimentally in plasma reactors (2). The response times of the two-color signals have been found to be too slow to be uselul for reliable measurement of cooling rates. Since absolute temperatures generally are determined by two-color measurements only, the most satisfactory way to obtain particle temperatures is the use of two-color measurements as the particle temperature rises and single-color measurements for cooling. The two-color measurements at the maximum point provide a calibration point for the single-color measurements. In this way it is possible to determine phase transitions and to quantify phase transformation rates in rapidly cooled particles. Further improvements are being made to the signal detection and processing circuitry to decrease the signal response time in cooling.

\section{B. Effects of Vaporization on Apparent Particle Temperatures}

Vaporization affects the energy required to heat a particle and the net heat transfer to the particle, and thus it influences significantly the temperature attained by particles in plasma jets. Measurement of particle temperatures in the hottest section of a plasma jet (within about $50 \mathrm{~mm}$ from the nozzle) is practically impossible due to the overwhelming radiative flux emanating from the plasma at temperatures above $5000 \mathrm{~K}(3)$. Consequently, the establishment of particle temperatires in this region must rely on simulations and modeling. Vaporization also affects the one-color radiation signal from particles through its effect on the projected area of the observed particle. The effect of vaporization and the temperature dependence of emissivities on the measured one-color temperature of an alumina particle heated above $3600 \mathrm{~K}$ have been determined. The results show the corrections necessary for onecolor measurements, and "hr"' have been employed to develop the methodology for calculation of vaporization rates from one- and two-color temperatures $(4,5)$.

\section{Preliminary Studies of Cobalt-Bonded Tungsten Carbide Particles}

A collaborative study with INEL has been initiated with the objective of generating fundamental understanding of the processes and mechanisms occurring during plasma spraying of cobalt-bonded tungsten particles; specific goals are to characterize phase transformations, measure vaporization rates, and determine the phase structures resulting from the processing of particles under conditions simulating plasma spraying. This system is of interest for practical
applications and is, at the same time, an interesting model system for the study of kinetics of 
phase transformations. Several transformations of interest occur in the system: melting and vaporization of cobalt, decomposition of carbides, and possibly formation of complex solid phases.

Pulse heating of composite WC+Co particles has been accomplished with 50 to 150 micrometer particles sintered to a fine tungsten filament. Repeated heating of the same particle and its easy recovery for phase analysis of the final product are possible. The typical time-temperature profile obtained by multiple pulse heating is shown in Figure 4. An irregular but reproducible emitted radiation signal at temperatures above the melting point of cobalt appears, but it disappears after repeated pulse heating. The cobalt phase apparently is completely vaporized at the end of this anomaly. The materials obtained from these ex reriments are currently being analyzed for phase structure and composition to help explain the anomalies in the observed temperature-time profiles.

\section{Materials Properties at Elevated Temperatures}

Several materials and material-laser beam arrangements have been tested with the aim of defining experiments conducive to the measurement of material properties of interest in diagnostic measurements on plasma processed particles. Principal among these are rates of vaporization and relative emissivities. It has been found that vaporization rates of solid materials can be measured conveniently for materials using thin fibers or filaments. Such experiments have been conducted on alumina, silicon carbide, and boron fibers. These same materials can also be used to measure the relative emissivities at different wavelengths in function of temperature, as is illustrated for the case of silicon carbide in Figure 5.

\section{PLANS FOR THE COMING YEAR}

The improved methods of temperature sensing that have been developed this year will be utilized to study the physical and chemical behavior of particles undergoing rapid heating and cooling; relative emissivities, vaporization rates as influenced by temperature and gas composition, and phase changes will be investigated. Emphasis will be placed on materials that currently are being processed in the plasma spraying studies by Dr. Fincke's group at the Idaho National Engineexing Laboratory. Examples are zirconia, Al-Ni alloys, and cobaltcoated tungsten carbides composites. Silicon carbide, boron, metal coated boron, boron carbide, and several hard-facing materials will also be included. The behavior of the pure components of these materials, e.g., aluminum, nickel, tungsten carbide and cobalt, will also be studied to provide a base of information for analysis of the behavior of the composite materials.

Photographic imaging of particles and fibers with the long-focus microscope will be utilized to evaluate the loss of cross-section (mass) because of volatilization. Particles will also be recovered for examination by photomicrography and electron optical methods. Selected particles and fibers will be sectioned by microtome for examination, one of the purposes being to ascertain if only partial melting of a material may occur in very rapis sating and cooling cycles even though the apparent temperature of the exterior of the particle may have exceeded the melting point of the material.

The temperature-time profiles chosen for study will include those measured in the plasma spraying experiments being carried out at INEL and those predicted in the modelling work of Professor Szekely's group at MiT. 


\section{REFERENCES}

(1) R.E. Spjut. "Transient Response of One- and Two-Color Optical Pyrometry Systems." Optical Eng., v. 26, pp. 467-472, 1987. (Att. 5)

(2) P. Fauchais, M. Vardelle, A. Vardelle, and J.F. Coudert. "Plasma Spraying of Ceramic Particles in Argon-Hydrogen Jets: Modeling and Measurement of Particles in Flight and Correlation with Thermophysical Properties of Sprayed Layers." Met. Trans., v. 20B, pp. 263-276, 1989. (Att. 36)

(3) J. Mishin, M. Vardelle, J. Lesinski, and P. Fauchais. "Two-Colour Pyrometer for the Statistical Measurement of the Surface Temperature of Particles under Plasma

Conditions." I. of Physics, v. 20, pp. 620-625, 1987. (Att. 37)

(4) P. Bolsaitis, R.E. Spjut, and J.F. Elliott. "High Temperature Pulses in Small Alumina Particles." High Temp.-High Pres., forthcoming. (Att. 1)

(5) P. Bolsaitis, R.E. Spjut, and J.F. Elliott. "The Measurement of Temperature of Particles Under Conditions Simulating Flash Smelting." Flash Reaction Smelting, D.G.C. Robertson, H.Y. Sohn, and N.J. Themelis, eds., The Center for Pyrometallurgy, Rolla, MO, 1988, pp. 319-330. (Att. 2)

\section{RECENT PUBLICATIONS}

P. Bolsaitis, R.E. Spjut, and J.F. Elliott. "High Temperature Pulses in Small Alumina Particles." High Temp.-High Pres., forthcoming. (Att. 1)

P. Bolsaitis, R.E. Spjut, and J.F. Elliott. "The Measurement of 'Temperature of Particles under Conditions Simulating Flash Smelting." Flash Reaction Smelting, D.G.C. Robertson, H.Y. Sohn, and N.J. Themelis, eds., The Center for Pyrometallurgy, Rolla, MO, 1988, pp. 319.330. (Att. 2)

J.R. Fincke, C.L. Jeffrey, and R.E. Spjut. "Measurement of the Emissivity of Small Particles at Elevated Temperatures." Optical Eng., v. 27, 1988, pp. 684-690. (Att. 3)

M.R. Libera, P.P. Bolsaitis, R.E. Spjut, and J.B. Vander Sande. "Liquid Supercoolings and Droplet Cooling Rates of Remelted Argon-Atomized Fe-30Ni Powder Particles." J. Mat. Res., v. 3, 1988, pp. 441-452. (Att. 4)

R.E. Spjut. "Transient Response of One- and Two-Color Pyrometry Systems." Optical Eng., v. 26, 1987, pp. 467-472. (Att. 5)

R.E. Spjut and P. Bolsaitis. "Three Channel Optical Temperature Measurement of LaserHeated Reacting Particles." Proceedings, Mat. Res. Soc. Symp., v. 87, 1987, pp. 295-303. (Att. 6)

R.E. Spjut, J.F. Elliott, and P. Bolsaitis. "Thermogravimetric Measurements in an Electrodynamic Balance." Proceedings, Mat. Res. Soc. Symp., v. 87, 1987, pp. 95-102. (Att. 7) 


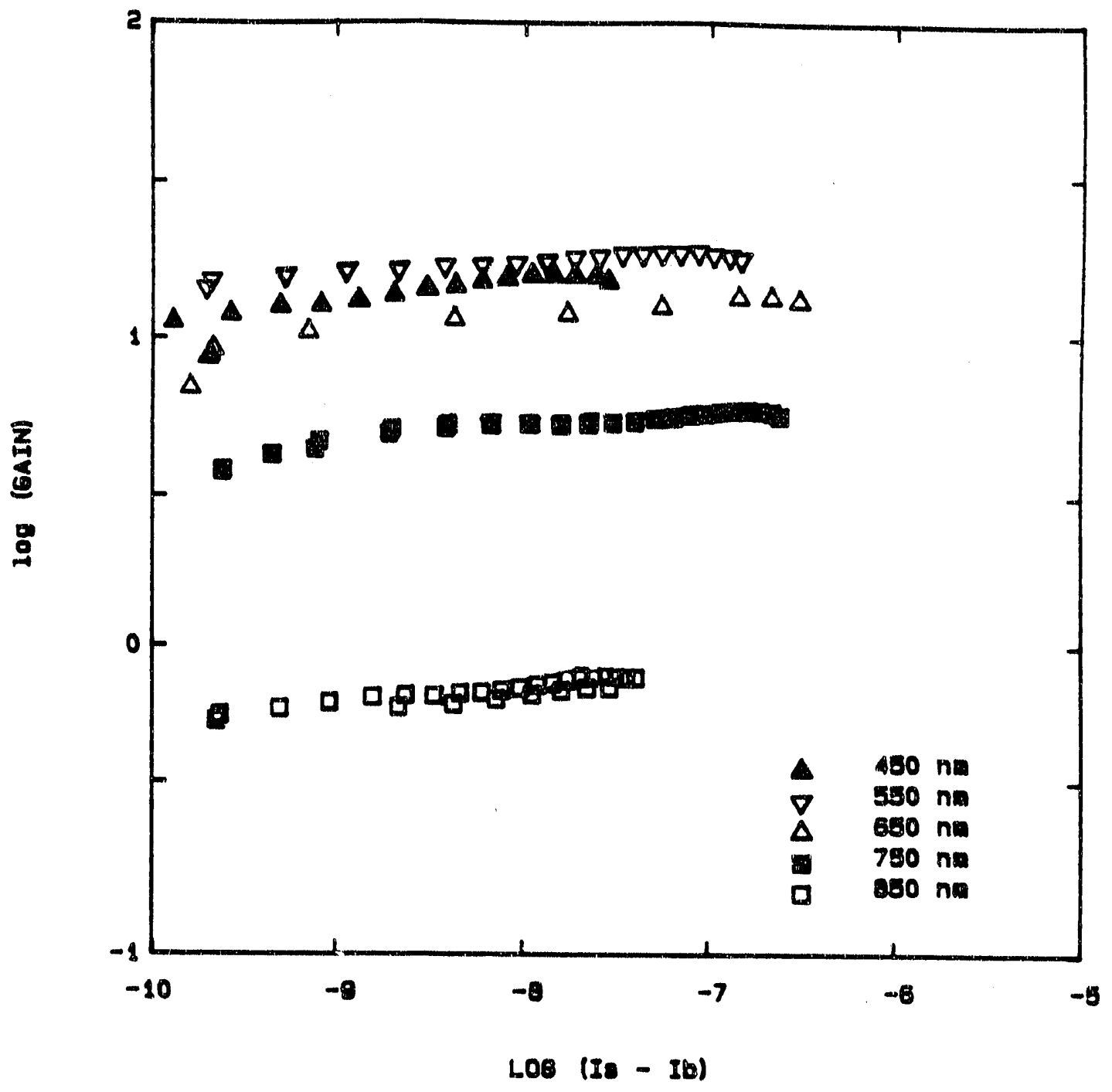

Fig. I SINELE COLOR CALIERATION CH.A 


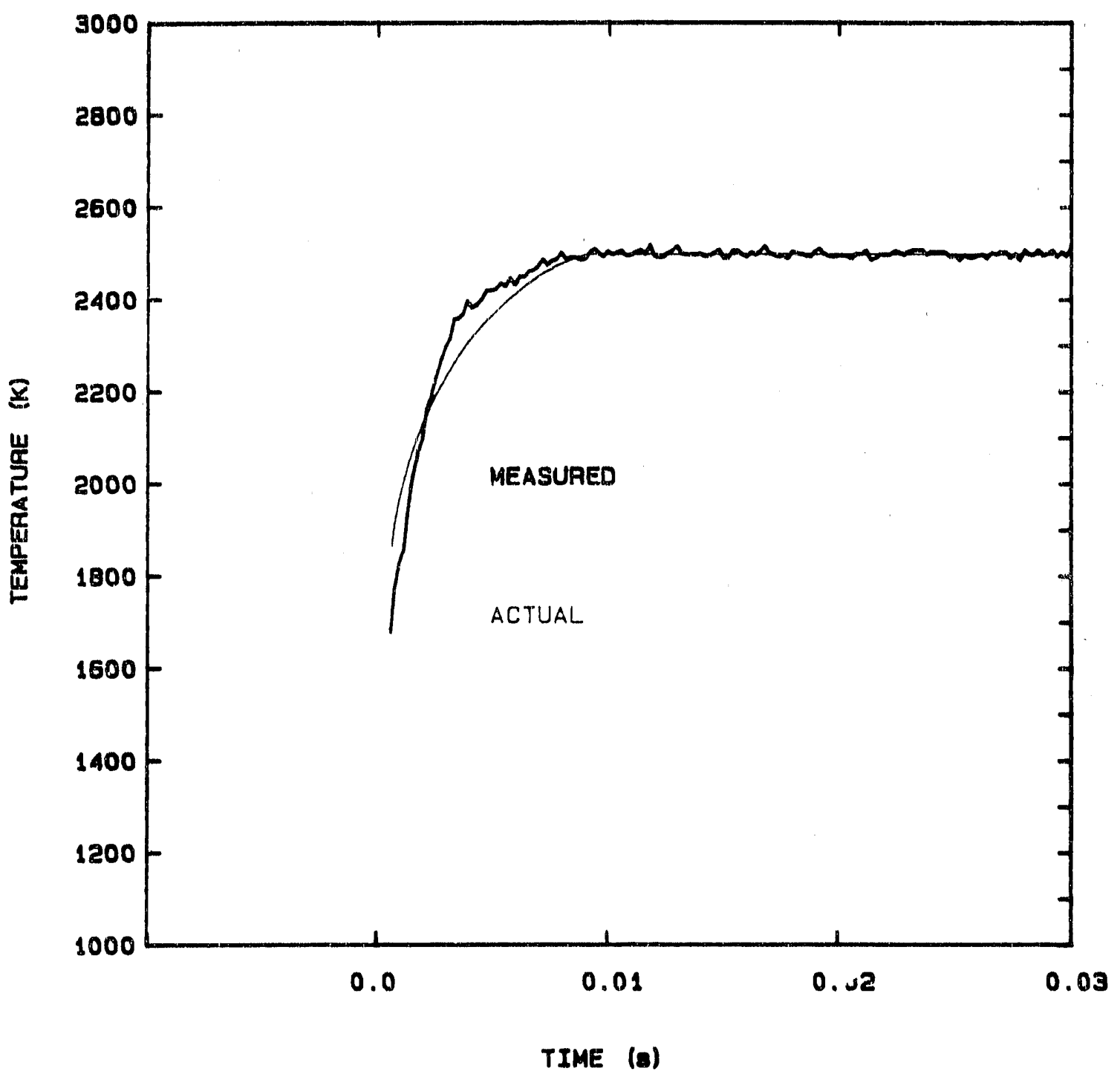

fig. 2 heating of paojecteo tungsten "paptigle"

(DATA: CET10.DAT; 5SONM) 


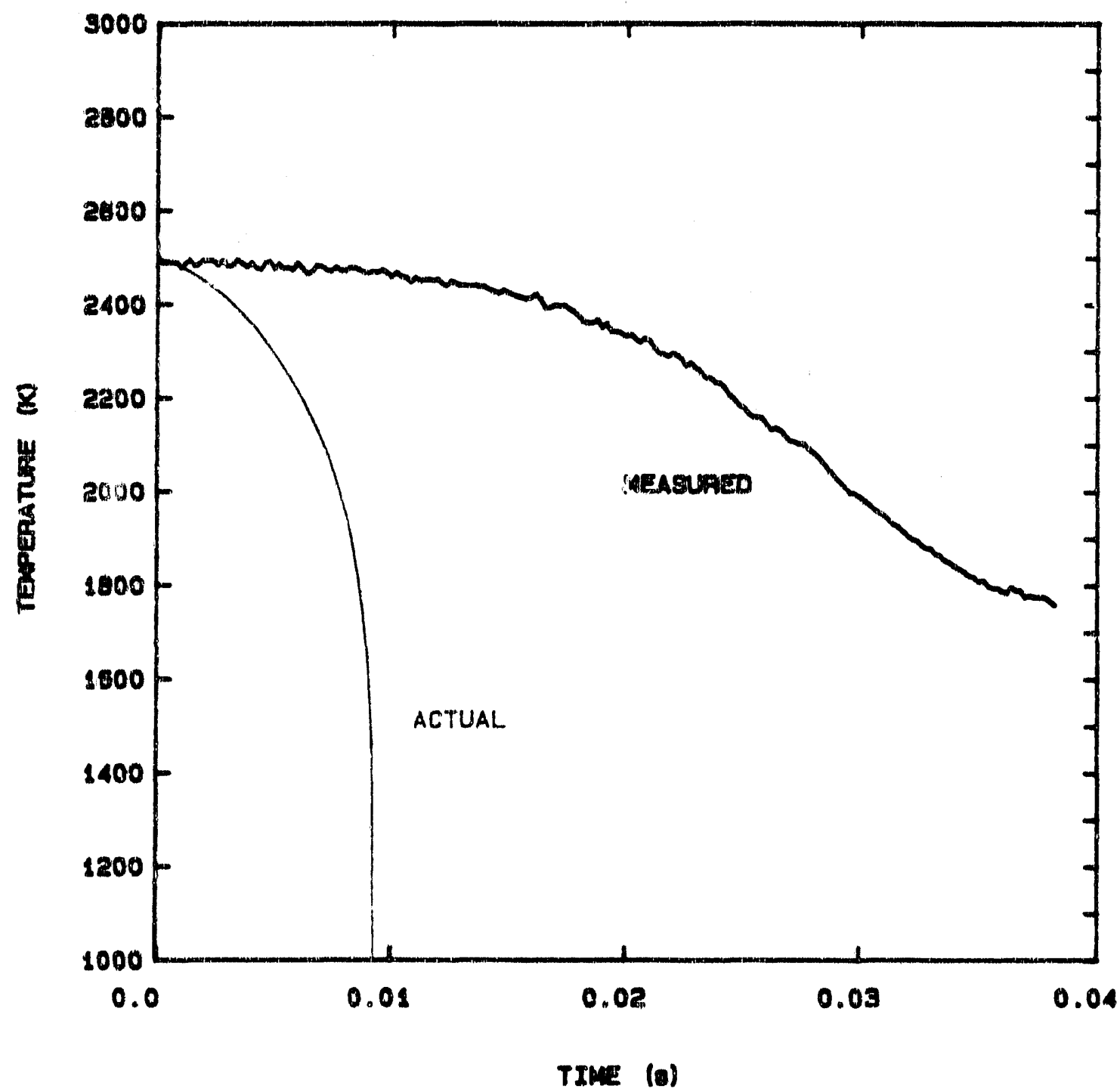

Fig. 3 cooline OF" PAOVECTEd TUNGBTEN "PAATICLE" DATA: CATAE.OATI 


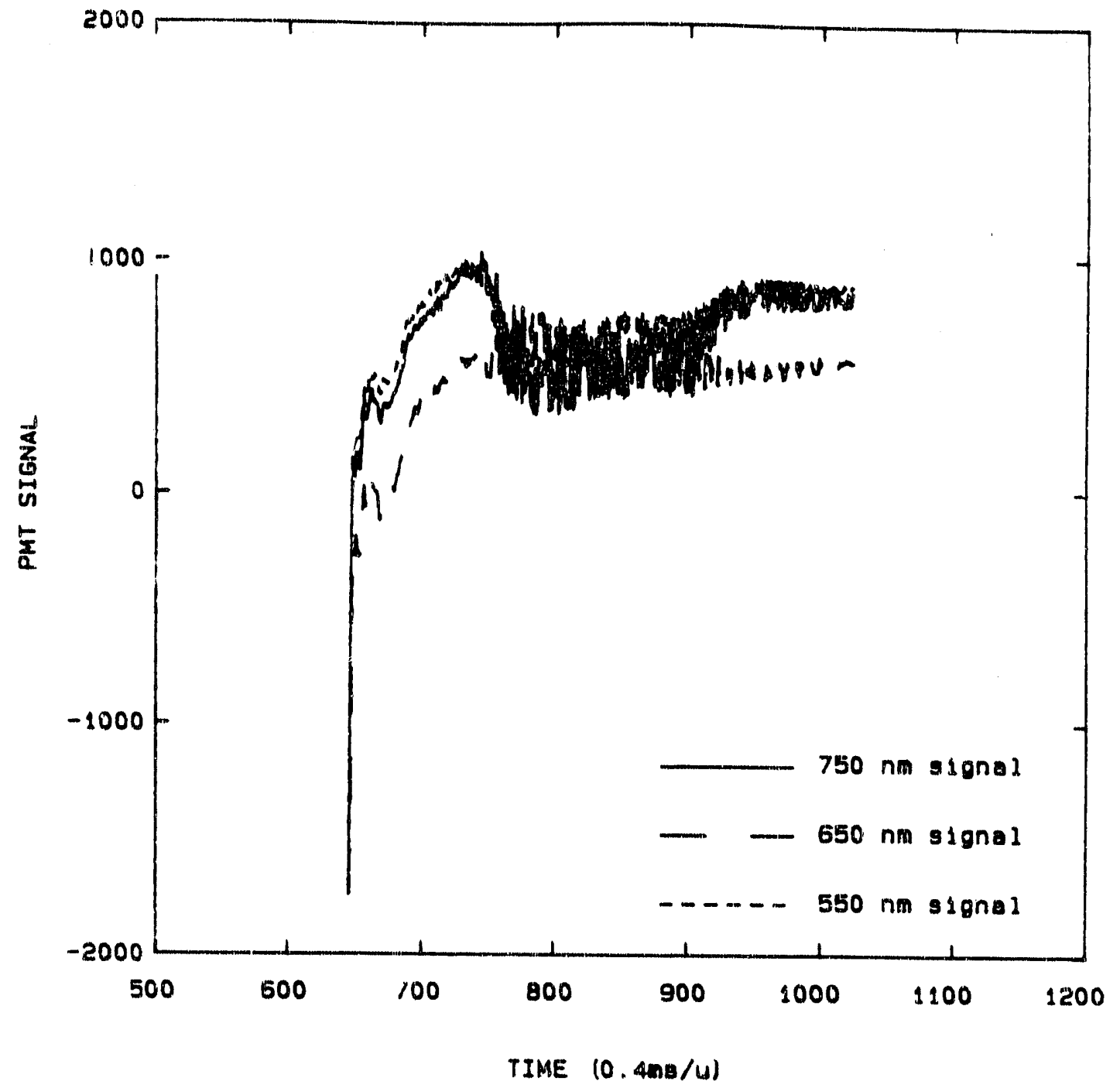

Fig. 4 HEATING OF TUNGSTEN CAABYDE + CA BINDER IN NITAOEEN lapprox. 150um particlel DATA: WCO5H.DAT 


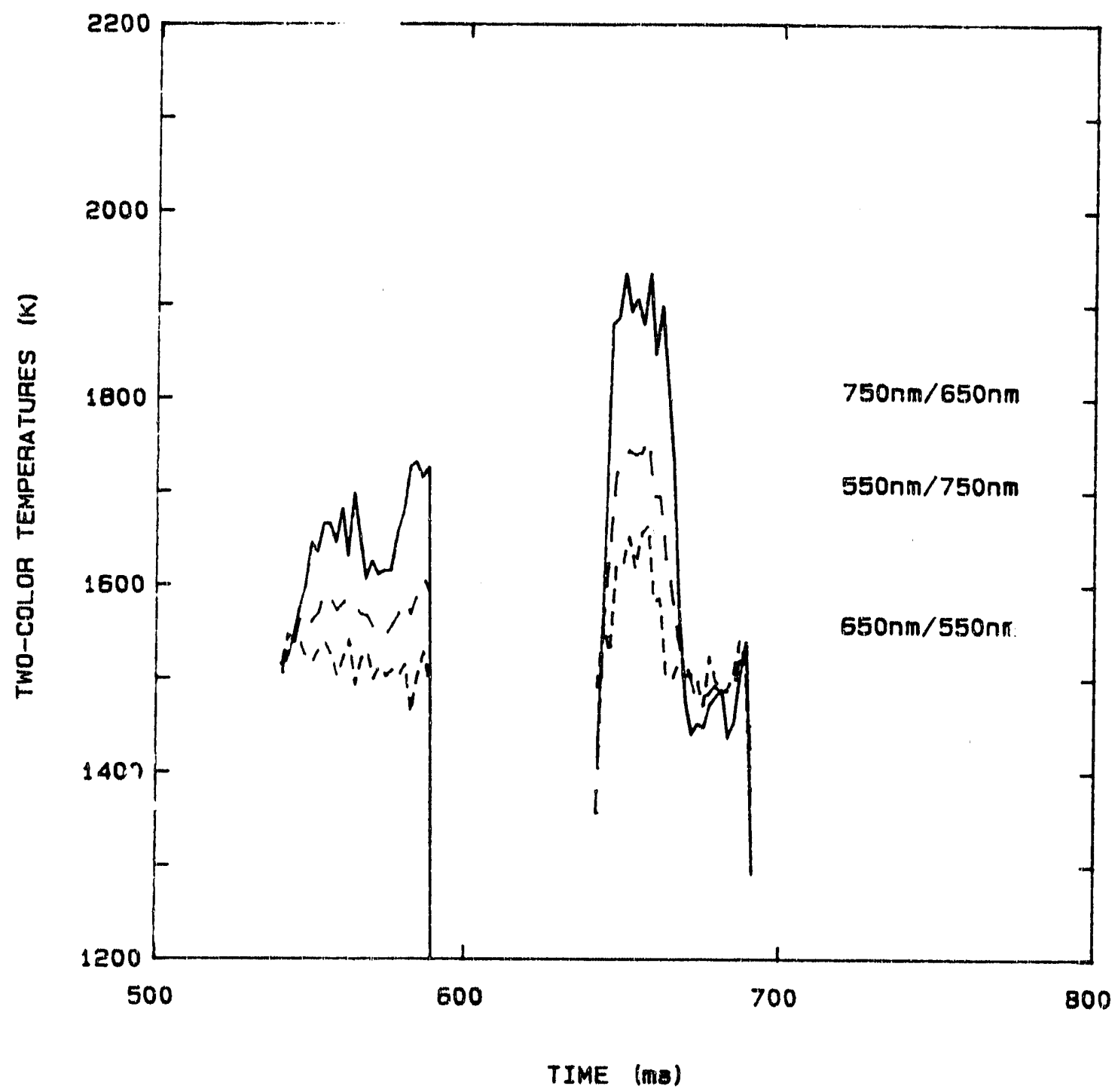

Fig. 5 APPARENT TWO COLOA TEMPERATURES OF SiC $100 \mathrm{~nm}$ FIBEA CALCULATED ASSUMING CONSTANT EMISSIVITY 


\section{MATHEMATICAL MODELIING OF PLASMA SYSTEMS}

\section{PERSONNEL}

Faculty:

Graduate Students:
J. Szekely, Department of Materials Science and Engineering

A.H. Dilawari, Department of Materials Science and Engineering

R.C. Westhoff, L.G. Trapaga

\section{ABSTRACT}

A comprehensive mathematical model is being developed to describe the electromagnetic, heat transfer, and fluid flow phenomena in plasma systems. At present the model is two-dimensional and axi-symmetric, with provision for swirl. The theoretical predictions for argon-argon systems are found to be in good agreement with measurements obtained by the researchers at INEL and also in France. More recent data concerning temperature and gas concentration profiles in an argon-nitrogen system have been represented. Additionally, an excellent start has been made in the modelling of plasma-particle interactions. Work currently in progress includes the study of the laminar-turbulent transition in the plasma plume and the behavior of the system inside the plasma torch.

\section{GOALS}

The purpose of this program is to develop a comprehensive mathematical representation of transport phenomena in plasma systems in close interaction with experimental work conducted by investigators at the Idaho National Engineering Laboratory and by researchers elsewhere. The measurements help to test and verify the model; at the same time, the modelling work helps in the planning, testing, and interpretation of the experimental measurements. Together the models and experiments will provide a better understanding of the physical phenomena that may occur in plasma spraying and plasma synthesis.

\section{PROGRESS}

The major accomplishments of the program to date include the following:

We have developed a realistic model for the plasma plume for both laminar and turbulent conditions, while addressing the following specific issues:

- swirl;

- realistic, highly temperature- and composition-dependent property values;

- full satisfaction of the heat and mass balances (this was not the case with previous studies).

As a result of this work we can predict the temperature, velocity, and concentration profiles in plasma plumes. These theoretical predictions were found to be in good agreement with measurements obtained by researchers at INEL and by Professor Fauchais in France and Professor Pfender at the University of Minnesota. 
We have developed a model that describes the plasma-particle interactions for dilute systems, accounting for particle dynamics and for particle heat transfer, including melting, solidification, and vaporization/evaporation. These results are now being compared with the experimental measurements conducted at INEL. The initial comparison has showed certain discrepancies, which are now being resolved.

We have developed a mathematical representation for axi-symmetric transferred arcs. The initial calculations were concerned with welding ancs because there is a good data base for comparing the theoretical predictions against measurements. This comparison has been successful and has led to the validation of the model. This model has been extended to conditions where the arcing occurs over a non-flat anode. Results from the extended model should be helpful in addressing transport phenomena inside plasma torches.

(4) We have initiated calculations describing electromagnetic and transport phenomena inside the plasma torch by making some rather sweeping assumptions regarding the arc shape. These calculations appear to be very promising in that they can satisfactorily predict experimental measurements obtained by the INEL researchers.

(5) We have initiated a program of study to examine the laminar-turbulent transition that takes place when a hot plasma jet discharges into cold surroundings. This transition is potentially very important because it can markedly affect the entrainment of gases by the plume. This work will require a major effort and the allocation of substantial amounts of supercomputer time.

\section{PLANS FOR THE COMING YEAR}

The plans for the coming year involve significant activity in all five areas outlined above. More specifically:

(1) We are planning to update the existing plume model in light of the simuitaneous velocity, composition, and temperature measurements that INEL is planning to supply us. At the same time, we are accessing additional measurements from Professor Fauchais' laboratory regarding temperature and composition measurements in nlasmas in order to obtain a more precise definition of the plume region.

(2) We shall continue with our modelling work of plasma-particle interactions. It is felt that this activity will require further refinement, particularly regarding the interaction coefficients between plasmas and particles (drag coefficients, heat and mass transfer coefficients). This work should benefit greatly from the experimental data that INEL will supply us, particularly regarding reliable plasma temperature measurements and simultaneous particle velocity, size, and temperature measurements obtained in the same torch. (At present this information is not fully available.)

We shall continue with our work to represent the electromagnetic and transport phenomena inside the torch and shall discuss experimental data that INEL may supply us in support of this effort.

(4) We shall continue our research concerning the laminar-turbulent transition in the plume. With the hoped-for acquisition of the Nippon Steel direct turbulence simulation package, this effort should gain major momentum. 
We shall be seeking to address non-equilibrium effects in plasma plumes. This effort, of course, hinges critically on experimental measurements and expertise that INEL can provide in the area of non-equilibrium plasmas.

Overall, the proposed activity will rely significantly on experimental data to be provided by INEL. However, we are also hoping to utilize measurements obtained by Fauchais. Furthermore, the work plan is organized such that the sometimes-inevitable delays in obtaining experimental measurements will not hold up our progress. This has been an important motivation for initiating the work on transferred arc systems and on heak and fluid flow phenomena inside the torch.

The same research team will be working on this program in the corning year. In view of the very heavy computational load and the budget cutback we suffered last year, we shall be seeking additional funds to provide partial support for the purchase of an advanced engineering workstation.

\section{RECENT PUBLICATIONS}

A.H. Dilawari and J. Szekely. "The Role of Transport Phenornena in the Plasma Synthesis of Fine Particles: The Production of Silicon Powder." Met. Trans. B, v. 20B, 1989. (Att. 8)

A.H. Dilawari, J. Szekely, J. Batdorf, and C.B. Shaw. "The Temperature Profiles in an Argon Plasma Issuing Into an Argon Atmosphere: A Comparison of Measurements and Predictions." Plasma Chemistry and Plasma Processing, forthcoming, 1989. (Att. 9)

A.H. Dilawari, J. Szekely, J.F. Coudert, and P. Fauchais. "Fluid Flow and Heat Transfer in Plasma Reactors. Part II: A Critical Comparison of Experimentally Measured and Theoretically Predicted Temperature Profiles in Plasma Jets in the Absence and Presence of Side Stream Injection." Int. J. Heat and Mass Transfer, v. 32, no. 1, 1989, p. 35. (Att. 10)

J. Szikely. "Transport Phenomena in Welds with Fmphasis on Free Surface Phenomena." Presented at the $2^{\text {nd }}$ International Conference on Trends in Welding Research, Gatlinburg, TN, May 1989. (Att. 11)

R.C. Westhoff. A Mathematical Model For Current, Heat Flux, and Pressure in a Welding Arc. S.M. thesis, MIT Department of Materials Science and Engineering, 1989. (Request copy if needed.) 


\section{AUTOMATED WELDING}


METAL TRANSFER IN GAS-METAL ARC WELDING

\section{PERSONNEL}

Faculty:

Research Staff:

Graduate Students:

Collaborator:
T.W. Eagar, Department of Materials Science and Engineering

Y.S. Kim, Department of Materials Science and Engineering

L. Jories

C. Allemand, Consultant

\section{ABSTRACT}

In order to automate the gas-metal are welding (GMAW) process, it is essential that one have a model of the electrode melting rate and the mode of metal transfer. In this study, the forces controlling droplet detachment from the electrode have been quantified and compared with previous theories. A modified static force balance was developed to explain the observed experimental trends. This analysis, coupled with a model of energy distribution in the electrode, provides an improved understanding of both constant current and pulsed current GMAW.

\section{SQAL}

The overall goal of the MIT-INEL. welding research program is to investigate methods of automating and controlling the GMAW process. This problem is compounded by the many non-linearities in the welding process. This specific project has the objective of defining the physics of electrode melting in arcs containing various shielding gases and different electrode materials under a wide range of welding conditions including pulsed current. Models are developed that should assist in dealing with non-linear control of the welding process.

\section{PROGRESS}

When this program was proposed six years ago, the initial research was centered on development of novel sensors for the monitoring and control of arc welding processes in general. Our initial research involved study of the optical spectra of aluminum, steel, and titanium welding arcs. This work showed that metal vapors are not distributed homogeneously throughout the arc, and in certain cases this distribution can produce arc instabilities. In addition, the arc spectra was mapped rnore thoroughly than had ever been done previously. This mapping provided windows through which the weld pool could be viewed more precisely. However, at the same time, research at INEL using stroboscopic weld imaging produced a clearer image of the pool. Although considerably more expensive than the filtering methods developed in the MIT work, the INEL approach showed much greater utility for research purposes; hence, the MIT program was modified. Nonetheless, the simplicity and affordability of the MIT approach may make it the choice for most commercial weld pool viewing systems.

Following these initial optical measurements of the arc, the MIT-INEL researchers agreed to concentrate future studies on gas metal arc welding. This project evolved into an investigation of electrode melting and metal transfer using some of the imaging technologies that were developed previously. 
During the past three years a comprehensive experimental and theoretical analysis of GMAW of aluminum, steel, and titanium in argon, helium, and carbon dioxide arcs has been undertaken. Initially, a study of anode spot attachment on different electrodes in different shielding gases was made using a laser backlighting technique developed at MIT and now in use by INEL and several other welding laboratories. These studies provided boundary conditions for modelling the forces controlling droplet detachment(performed during the second year) and for development of both a thermal analytical and a numerical model of the melting process (performed during the current year). The results of these thermal models have been compared with experimental measurements of electrode melting rates performed earlier under this program.

In studies from previous years, it was shown that the anode spot in argon shielding gases on all three metals is much more diffuse than in helium and carbon dioxide shielding gases. Experimentally it was shown that this diffuse anode spot causes $10-20 \%$ of the arc current to impinge on the cylindrical sidewalls of the electrode, producing a tapered tip. The formation of this tapered tip results in a discontinuity in the rate of melting with increasing weld current, which in turn results in a change of the mode of metal transfer. Using the analytical and numerical models developed during the past year, this experimental hypothesis has been shown to be correct. In addition, the model has quantified, for the first time, the relative rates of heat transfer and generation in the electrode due to i) Joule heating, ii) electron condensation on the solid electrode and iii) heat transfer through the liquid droplet. Using this insight, experiments were begun during the past year on pulsed current welding. By varying the pulse frequency and measuring the formation of the taper using the high speed cinemaphotographic technique, a new method of predicting the range of acceptable pulsing parameters was developed. It was shown that prevention of a fully developed taper on the electrode tip during pulsed current welding can increase the rate of melting per unit of current by up to twenty percent. When the taper becomes fully developed, streaming transfer results and pulsed current welding has no advantage over DC welding. This new model of the useful range of puise current welding can be applied to the control strategies being developed in the INEL equipment.

In addition, this physical model of how current puising influences both electrode melting rate and droplet detachment mode has been used to explain why ternary gas mixtures of argon-helium-oxygen and argon-carbon dioxide-oxygen produce higher melting rates and more stable metal transfer than the commonly used binary gas mixtures. Addition of carbon dioxide or helium to argon constricts the anode spot, thus inhibiting the formation of a fully developed taper on the electrode tip. This significantly broadens the range of useful pulsing frequencies and makes control of the welding process easier to achieve.

Finally, an approximate analysis of heat transfer and convection within the liquid droplet itself (rather than the electrode as a whole) was begun. Preliminary results show that convective heat transfer within the droplet is likely to be significant and that this problem will require a transient solution. Thus, the approximate analysis suggests that further studies of the details of droplet heat transfer behavior will be difficult at best and that research in other areas (such as droplet dynamics) is likely to be a more fruitful area of research. 


\section{PLANS FOR THE COMING YEAR}

The model of pulsed current welding agrees well with experiments when the peak current does not exceed twice the base current and when the base current is less than 200 amperes. However, the model deviates from the experiments when higher currents are used. It is believed that this deviation is due to dynamics within the liquid drop that are not considered in the current model. During the next year, a new set of experiments using pulsed welding currents will be performed to determine the drop dynamics. These details will then be incorporated into a revised model that should be capable of defining the optimum pulsing parameters over a wider range than is currently possible.

\section{RECENT PUBLICATIONS}

T.W. Eagar. "An Iconoclast's View of the Physics of Welding-Rethinking Old Ideas." Proceedings from the 2nd International Conference on Trends in Welding Research, Gatlinburg, TN, May 14-18, 1989. (Att. 12)

S. Eickhoff and T.W. Eagar. "Characterization of Spatter in Low Current GMAW of Titanium Plate." Submitted to Welding Journal, 1989. (Att. 13)

Y.S. Kim. Metal Transfer in Gas Metal Arc Welding. Ph.D. thesis, MIT Department of Materials Science and Engineering, Cambridge, MA, June 1989. (Request copy if needed.)

Y.S. Kim and T.W. Eagar. "Modelling of Metal Transfer in Gas Metal Arc Welding." Edison Welding Institute Members Seminar, Cambridge, MA, September 1988. (Att. 14)

Y.S. Kim and T.W. Eagar. "Temperature Distribution and Energy Balance in the Electrode During GMAW." Proceedings from the 2nd International Conference on Trends in Welding Research, Gatlinburg, TN, May 14-18, 1989. (Att. 15) 


\section{MULTIVARIABLE CONTROL OF GAS-METAL ARC WELDING}

\section{PERSONNEL}

Faculty:

Research Staff:

Graduate Students:
D.E. Hardt, Department of Mechanical Engineering

A. Sharon, Laboratory for Manufacturing and Productivity

M. Hale, J.B. Song

\section{ABSTRACT}

This research is aimed at developing a comprehensive approach to control of welding processes, and GMAW in particular. Our working context has been linear system theory and causal modeling of dynamic systems. The main efforts this year have been on modeling and control of weld geometry, in particular the bead width, height, and depth. Both an analytical and empirically-based model have been developed that indicates welding-velocity-dependent system dynamics, and highly non-linear steady-state characteristics. More importantly, the controllability of the process has been shown to be very poor. In particular, both the strong coupling among geometric features and the small range of acceptable modulation greatly limit control efforts. Despite these problems, several multivariable control systems were developed and tested. Experiments have confirmed the validity of the models and indicated that future research may have to consider redesign of the process to enhance controllability. Also during this year we have initiated a project aimed at real-time estimation of pool depth based on surface temperature measurements.

GQAL

The objective of this research is to develop the fundamental basis for controlling multiple outputs of the gas-metal arc welding (GMAW) process. The approach is to use the theoretical framework of linear multivariable systems as the context for process modeling, measurement selection, and control system design. The work has been divided into two distinct but physically related segments, namely, control of thermally activated properties of welds and control of weld bead geometry.

\section{PROGRESS}

Work on the thermal aspects of the GMAW process was completed early this year with the development of dyradi.a. prucess models for heat-affected zone (HAZ) and cooling rate (CR) control. These models (see attachment 16) were based on a unique combination of numerical methods and linear system identification techniques. The former was used to completely capture the non-linear, distributed parameter nature of the thermal system, while the latter was used to transform this field model into a lumped parameter, non-stationary input-output model for control design purposes.

This model has been used to develop a self-tuning control system that regulated both $\mathrm{HAZ}$ and $\mathrm{CR}$ to desired values independently. While the control range is limited for a given welding situation, the results of both simulation and experiments have demonstrated the ability of this systern to reject important process disturbances such as changes in material properties, material thickness, and thermal boundary conditions. 
Parallel work on geometry modeling and control has concentrated on modeling of the process with pool width, depth, and reinforcement height as outputs. This work began with an analytical approach, but we found that thr: basic physics of arc/droplet-pool interaction are not well enough understood to base a control model on first principles. Accordingly, we have developed an empirical model that captures both the static and dynamic nature of the process.

We developed this model in the form of a non-stationary linear difference equation. As such, it can be used directly in a real-time control and real-time identification scheme to permit continuous re-calibration of the model as the system parameters change. In this way the essential non-linearities of the process, which are characteristically boundary condition changes or material property changes, can be accounted for through model parameter adjustinent.

During the past year, the geometry problem has been dominant with the model and control efforts culminating in demonstration of real-time regulation of two variables, maximum pool width and pool height. Although the process model has been developed to include pool depth $\dot{\text { s }}$ an output, we developed the data for that model using destructive sectioning of weld specimens, since no reliable direct measure of depth is yet available. Accordingly, this year we have also begun an effort aimed at developing a real-time estimator for depth based on indirect measurements (surface geometry and temperatures).

\section{A. Geometry Control}

The model of pool geometry development has shown that the process dynamics, although non-linear with welding velocity, are rather well-behaved. (There are, however, non-negligible process delays that place limits on achievable process gains.) On the other hand, the static behavior of the process is not well-behaved, and much of our work this year has been on understanding these problems and on developing control systems based on knowledge of these problems.

The basic difficulty in controlling multiple geometric attributes in GMAW is that multiple scalar measurements of pool geometry are all never truly independent but rather are different dimensions of a single pool volume. The key physics, then, are related to how the pool volume is developed and how its basic shape is changed. For the case under study here, the pool width and height are determined primarily by the addition of filler material from the consumable electrode.

In examining the static behavior of the process, it has been found that for all possible process inputs (including wire feedrate and torch velocity), the outputs of width and height are highly coupled; and very little latitude exists to exert independent control. For example, while it is possible to vary the pool height over a reasonable range (provided no constraint is put on width), when width is fixed, the modulation range for height is reduced to about $20 \%$ of the total possible range. The same effect is present with width as output, but the reduction is to about $30 \%$ of full range. Interestingly, if depth is used as one of the outputs, greater independence is achieved, owing to the difference in dominant heat transfer mechanisms for penetration versus width formation.

A second, potentially more severe problem is that input-output pairs are nonunique, such that for any desired width and height combination, the corresponding inputs can assume two different sets of values. For a control system, this non-uniqueness can cause a system to be bi-stable and possibly cause it to "hunt" between the two possibilities, never fully achieving steady-state. However, if the input range is further restricted, this range of bi-stable behavior can be avoided, albeit at the expense of further compression of the operating range. 
We explored several control schemes including: 1) independent linear regulators for width and height, 2) scheduled gain controliers (to account for the velocity-dependent dynamics), 3) decoupling controllers (where the static decoupling is explicitly accounted for and truly independent processes are developed), 4) decoupling controller with a Smith-Predictor mode to account for process delays. In both simulations and experiments we found that any single variable could be well controlled, up to the limit of stability caused by delays. However, when two-variable control was attempted, the problems of severe static coupling came forward; and performance was mixed. The bi-stable behavior was observed and found to be strongly dependent on operating point and control system gains. The decoupling controller achieved the best overall performance but was highly sensitive to errors in the decoupling matrix.

Disturbance rejection, a key concern with welding control systems, was not satisfactory. The key factor was again the limited range of possible operation. A parameter disturbance (such as a plate geometry change) would essentially shift the input-output relationship; and since the range of operation was so limited, this shift typically moved the operating region to an unachievable point. Thus only small disturbances could be rejected.

The conclusion at this point is that multivariable control is possible and that our models are quite in Jequate for the task. However, the conventional GMAW process is lacking in control latitude sufficient to give an acceptable range of operation; and work on increasing the decoupling of the process is necessary.

\section{B. Depth Estimation}

Based on earlier work, we have begun development of a process model that will permit prediction of pool cross-sections based on measurement of the external temperature filed on the weldment. To achieve this, an analytical heat transfer model has been developed that can be calibrated to predict accurately the types of pool cross-sections that are typically encountered in GMAW. Since these are not uniform cross-sections but rather have a large penetration "finger" imposed on a smoother elliptical shape, a multiple heat source model is required. The concept is, then, that the multiple heat source model can be adjusted to create the correct conduction isotherms in the weldment for the weld in process. These isotherms can then be sensed directly from the top and bottom surfaces of the weldment. By matching measured isotherms with those predicted by the analytical model, the model parameters can be tuned to appropriàte values. Once tuned, the internal isotherms predicted by the model can be interrogated to determine the pool cross-section. Using this scheme, a continuous pool cross-section estimator can be developed that will use surface temperatures as inputs. We have completed development of the analytical model and are currently examining our ability to tune the model on the basis of both simulated and measured surface temperatures.

Interaction between our work at MIT and efforts at INEL continues to be strong and mutually beneficial. The main tasks at INEL are focused on sensing methods for control of GMAW and on exploring more heuristic methods of controlling the process to provide near term gains. Our collaboration in terms of intellectual guidance has been quite close, with their work on control helping to elucidate alternative approaches to the problem, and our work giving them input as to a broader basis of the process control based on process modeling. The sensing work has had an even more direct impact on our work. The INEL expertise in video sensing has been used several times to aid in the setup of MIT experiments, and we have in turn helped INEL sharpen the goals for their pool sensing efforts. The other INEL efforts in ultrasonic sensing have helped us define what additional measurements may be available in the future and what can be done in the near term. 


\section{PLANS FOR THE COMING YEAR}

In the next year we expect to complete the depth estimator and to attempt to control depth in a real-time fashion. In addition, we expect to attempt rnultivariable control of a single geometry and single thermal variable (i.e. the HAZ). The latter will require merging the two models that have been developed, and the problem of input-output latitude will again have to be addressed.

\section{RECENT PUBLICATIONS}

C.C. Doumanidis. Modeling and Adaptive Control of Thermal Properties During Welding. Ph.D. thesis, MIT Department of Mechanical Engineering, February 1988. (Request copy if needed.)

C.C. Doumandis and D.E. Hardi. "A Model for In- Process Control of Thermal Properties During Welding." J. of Dynamic Systems, Measurement and Control, March 1989. (Att. 16)

C.C. Doumanidis and D.E. Hardt. "Multivariable Adaptive Control of Thermal Properties During Welding." To be published in J. of Dynamic Systems, Measurement and Control, 1990. (Att. 17)

C.C. Doumanidis and D.E. Hardt. "Simultaneous In-Process Control of Heat Affected Zone and Cooling Rate During Arc Welding." In review for The Welding Journal, June 1988. (Att. 18)

M. Hale. Multivariable Control of a GMA Welding Process. Ph.D. Thesis, MIT, Department of Mechanical Engineering, September, 1989. (Request copy if needed.)

A. Suzuki, D.E. Hardt, and L. Valvani. "Application of Adaptive Control Theory to On-line GTA Weld Geometry Regulation." Presented at the ASME Symposium on Control Issues in Manufacturing Processes, December 1988. (Att. 19)

A.S. Tam and D.E. Hardt. "Weld Pool Impedance for Pool Geometry Measurement: Stationary and Non-Stationary Pools." J. Dynamic Systems, Measurement and Control, forthcoming, June 1990. (Att. 20) 


\section{ENGINEERING ANALYSIS}




\title{
SYNTHESIS OF HEAT AND WORK INTEGRATION SYSTEMS FOR CHEMICAL PROCESS PLANTS
}

\section{PERSONNEL}

Faculty:

L.B. Evans, Department of Chemical Engineering

Graduate Students:

S. Sundaram, M. Viswanathan, H.J. Yoon

\begin{abstract}
This research is aimed at developing improved methodologies for the synthesis of heat and work integration systems in process plants. In a typical plant, such as a petroleum refinery, a petrochenical plant, or a paper mill, many process streams must be heated or cooled in heat exchangers. The heat integration system recovers heat from streams that must be cooled and transfers it to streams that must be heated. A plant also requires energy in the form of work to drive pumps and compressors and to meet other mechanical energy needs. This work must be supplied externally, such as by purchasing electricity from a utility or generating it internally within the plant. The goal of work integration is to identify process modifications involving work interactions with the process that can reduce the total cost of energy in the plant.
\end{abstract}

\section{GOALS}

The goal of this work is to develop computer-based methods to help engineers perform the process synthesis task. The strategy is to combine modern mathematical programming techniques; sophisticated rigorous models of the process, utilities system, and heat recovery network; and heuristic methods to develop an overall methodology that is more powerful than traditional approaches. Although this field has been the subject of intense interest and research in chemical engineering over the past decade, most work reported in the literature has dealt with idealized systems. A focus of our research has been to develop algorithms to deal with the constraints and nonidealities that characterize industrial processes. The objective is to develop new generic methods and to demonstrate them with prototype software. Methods and programming techniques of artificial intelligence are being used where appropriate. The net result of this research will be an improved understanding of the nature of the problem of energy integration in process plants. The methods being developed will help engineers solve realistic industrial problems.

\section{PROGRESS}

Murali Viswanathan completed his doctoral thesis research during the past year (see publications list). The objective of his thesis was to develop methods to synthesize heat exchanger networks for constrained and nonideal chernical processes.

In many plants, certain heat exchange matches are forbidden because of safety or because the streams are located far apart in the plant. In the thesis, new problem formulations based on the transshipment and transportation models of operations research were developed to determine targets for the minimum utilities, minimum number of heat exchanger units, and minimum total heat transfer surface area. The new formulations apply both to constrained and unconstrained problems. 
The presence of a constraint will generally result in an increase in the minimum utilities, minimum units, or minimum surface area targets. A systematic methodology was developed to analyze the possibility of minimizing the cosisequences of forbidden match constraints. This is based on the use of one or more process streams to behave both as a hot and cold stream (dual stream). The net result was the discovery of new, hitherto unknown, lower cost heat exchange network structures. The strategy could also be extended to deal with preferred and restricted matches.

All of the previous methods for synthesizing heat recovery networks have dealt only with utilities at a constant temperature, such as condensing steam. Many utilities, such as cooling water, undergo a temperature change in the process. We refer to these utilities as nonpoint-temperature utilities. A method was developed to incorporate such utilities within the framework of the transshipment models. The method leads to an accurate estimate of the mass flow rates and final temperatures of the utilities, the number and location of pinch points, the heat exchanger area, and number of matches.

A new method has been developed to establish surface area targets in the presence of constraints. It is based on solving a nonlinear model and can predict the area accurately in the presence of forbidden matches, nonuniform heat transfer coefficients, and also when the heat exchanger material costs per unit area are not uniform but depend on the strearns being matched. Using the area prediction model, a formulation to minimize the number of matches and area simultaneously has been developed.

The area target establishment method was used to resolve the tradeoff between decreased operating cost and increased capital cost on using dual streams. The Gain Maximization theory was developed for this task. It was extended to determine the appropriate sequence of dual strearns if multiple dual streams were allowed for mitigating the effect of forbidden matches.

Finally, Viswanathan formulated a method to optimize the process simultaneously along with the heat exchanger network in the presence of constraints. It is based on a new model that has been developed to establish the minimum utilities target. The model does not need the explicit definition of temperature intervals a priori.

In the area of work integration, the focus of the ongoing doctoral thesis work of Hyung Yoon has been on methodologies that consider the effect of work interactions on the process. For a plant that produces or requires a significant amount of mechanical energy in the form of work, decisions regarding synthesis of the work-producing and -consuming portions of the process usually dominate those decisions related to the design of the heat recovery network, from the standpoint of economics.

Our research seeks to consider simultaneously the placement of work-producing and -consuming units with synthesis of the heat recovery network. This usually leads to simultaneous design of the plant utilities system and the heat recovery network. A thermodynamic targetting technique has been formulated using availability analysis. Systematic methods have been developed for the placement of pressure-changing devices and the introduction of heat engines and heat pumps.

A mathematical formulation of the work integration problem has been developed that leads to solution of a series of subproblems based on mixed integer linear programming (MILP). The set-up of the problem is facilitated by the use of a set of heuristics or rules in an expert system framework. Finally, the solution of the work integration problem is interfaced with standard methods for synthesis of the heat recovery network. 


\section{PLANS FOR THE COMNG YEAR}

In the coming year we expect to complete Hyung Yoon's work on synthesis of work integration systems. With the completion of three doctoral theses on the project, Richard Wilcox (1985), Muraii Viswanathan (1989), and Hyung Young (expected 1990), we will have made substantial progress on developing new methodologies that combine the use of rigorous simulation models, mathematical programming techniques, and heuristic methods from artificial intelligence for synthesis of heat and work integration systems in large commodity plants.

A major redirection of the process industries in the past few years has led to increased emphasis on manufacture of high-value speciality products as opposed to bulk commodity products. These are usually made in batch and semi-continuous plants; the rapidly growing biotechnology industry is a prime example. Most existing methods of process synthesis, however, have focused on the large commodity plants and on continuous plants operated at steady-state. In 1990, we propose to reorient our work on process synthesis to address the problem of synthesis of batch and semi-continuous processes. Suresh Sundaram will investigate the problem of synthesis of batch separation systems as his doctoral thesis under this project.

\section{RECENT PUBLICATIONS}

M. Viswanathan. Synthesis of Constrained and Nonideal Heat Exchanger Networks in Chemical Process Plants. Ph.D. thesis, MIT Department of Chemical Engineering, June 1989. (Request copy if needed.)

M. Viswanathan and L. B. Evans. "A Methodology for Establishing Surface Area Targets for the Synthesis of Constrained Heat Exchanger Networks." Seventh Symposium on Energy Engineering Sciences, Argonne, Illinois, June 1989. Also submitted for publication in Computers and Chemical Engineering (1989). (Att. 21)

M. Viswanathan and L. B. Evans. "Simultaneous Optimization and Heat Integration of Chemical Processes in the Presence of Constraints," accepted for presentation at the AIChE Annual Meeting, San Francisco, November 1989. (Att. 22) 


\section{PARITY SIMULATION OF DYNAMIC PROCESSES}

\section{PERSONNEL}

Faculty:

Research Staff:
K.F. Hansen, Department of Nuclear Engineering

E.V. Depiante, Department of Nuclear Engineering

\section{ABSTRACT}

The analysis of transients in complex systems almost always requires the use of simulation tools. Although analog computers have been used for dynamic simulation, the traditional approach involves the use of digital computers. This project is engaged in developing an alternative approach known as parity simulation. Parity simulation, which originated in the study of electronic network transients, exploits the concept of electrical analogs to physical systems. Electrical analogs of the components of a system are constructed and interconnected in a manner that is in topological parity with the physical system. The resulting simulator system appears to the user as a model of the physical system. Communication occurs in the natural language of the user, which enhances the ease of use and interpretation of results.

\section{GOALS}

The first goal of the project was to develop electronic analogs to fluid system components such as might be encountered in nuclear power plants. The components to be simulated included pipes, pumps, heat exchangers, and nuclear reactor cores. The second goal of the project was to determine what degree of physical and mathematical complexity could be represented by electronic analogs. The range of complexity in fluid models includes single phase and multiphase flow. The third goal was to determine the applicability of the parity simulation concept to the analysis of transients in nuclear power plants.

\section{PRQGRESS}

In previous work, we created a systematic procedure for developing electrical analogs for parity simulation. The procedure consists of the following steps. Initially, a plant component for which an electrical analog is sought is identified and its boundaries defined. A mathematical model for this plant component is then formulated using fundamental physical laws. Mass, momentum, and energy balances and state and other relevant equations are stated and recast into a form suitable for the following step. An electrical analog for the developed model is proposed. The circuit equations for the electrical analog are the same as those of the mathematical model. The electrical analog is inspected to identify non-standard electrical components. For example, nonlinear models give rise to nonlinear components in the electrical analog. Implementation of these components is addressed using current electronic technology. Finally, the electrical analog may be built and used to simulate the desired component.

Following this systematic procedure, we designed and constructed parity simulator elements for the following physical plant components: incompressible and compressible singlephase and two-phase pipe sections, a steam generator, and a stearn separator. Application of this procedure to individual components is reported in the literature $(1,2)$. For example, the 
current two-phase pipe section uses a homogeneous model while accounting for nonlinear pipe friction and fluid inertia. In addition, the above elements were linked together to simulate more complex systems, including a pressurized water reactor primary loop and the boiling water reactor internal recirculation paths in the reactor vessel.

\section{Two-Phase, Two-Fluid Systems}

An important aspect of parity simulation is the complexity and generality of models that it can successfully accommodate. In particular, within the therntal hydraulics domain, it is necessary to determine whether use of models more elaborate than a two-phase homogeneous is feasible. A two-phase, two-fluid system was selected as a prime example of an elaborate model to investigate this issue.

The physical system under consideration is two-phase flow through a pipe section. The mathematical model used consists of a two-phase, two-fluid, six-equation model. Balance equations include mass, momentum, and energy for both liquid and vapor phases. Constitutive equations include interfacial mass, momentum and energy transfer, and wall momentum and energy transfer. Body forces are included. On the basis of this model, the circuit diagram of an electrical analog is conceptually designed.

Implementation requires a number of nonstandard components. Some implementation considerations follow. A number of wall and interfacial terms require controlled nonlinear resistors dependent on several parameters. Controlled resistors are implemented using tables. However, this quickly becomes impractical since the table size (bytes) grows exponentially with the number of external parameters. Thus table dimensionality becomes a limiting factor unless a conventional analog or other approach is used. The determination of pressure for the six-equation model requires a feedback loop. The stability of this loop solving a nonlinear

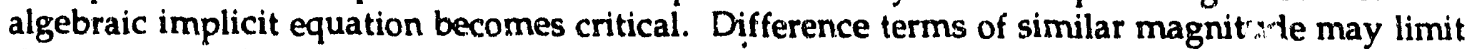
the accuracy. An energy balance term of the $p \dot{V}_{l}$ form requires differentiation, wilh potential noise problems.

In conclusion, it is found that while design is in principle still possible as model complexity increases, the fraction of auxiliary analog computations increases, the amount of information transfer (overhead) increases, table dimensionality becomes a limiting factor, algebraic loops may limit stability or accuracy, and the total number of tables used increases (propagation of discretization errors). Practical factors such as testing effort and cost must be also considered. This suggests a practical limit to model complexity.

\section{Increased Performance of Parity Simulation}

An area of interest is that of increased performance in the parity simulation of thermal hydraulic systems. This problem is attacked on two fronts: examination of analog-signal representation alternatives and finite nodalization effects.

The advantages of parity simulation include parity (modularity), true timeintegration, and computational parallelism. A disadvantage of parity simulation is its analog-signal nature, manifest in noise, dynamic range, resolution, of fsets, and similar effects. The problem is the inherent error of analog signal representation of the analog parity simulator. To achieve increased performance by reducing error, two alternatives are possible: (a) retain the analog-signal nature by use of better and costly components, or (b) switch to a digital format such as a digital parity simulator. The second one is explored further. 
A digital parity simulator has been proposed as a successor of the current (analog) parity simulator. Its structure consists of $\mathrm{N}$ independent processors, each assigned to a system/circuit component (physical partitioning), which may cornmunicate with each other. During operation each processor uses present state information to generate next-time-step information; new values are communicated to other processors, and the cycle is repeated. Integration algorithms such as forward Euler or predictor/corrector are used.

The implementation hardware uses digital signal processing (DSP) chips as fast costeffective processors, on a shared bus (Nu Bus; $N \leq 16$; Bandwidth $=37.5 \mathrm{MB} / \mathrm{s}$ ) and a Macintosh II host. The software is written mostly in $\mathrm{C}$ with some in Lisp. A simple four-pipe loop system is taken as an example to study how it would be simulated on the proposed digital parity simulator.

A number of issues must be addressed. The speedup is dependent on the load balance (even partitioning being the best) and on the communication vs. computation balance, which is partly hardware dependent. Thus, there is a need to "tune" to achieve optimal performance. More importantly, the parity concept is not fully preserved using this approach.

In conclusion, in the digital parity simulator, the parity concept is not fully preserved; speedup is not guaranteed; and efficiency depends on the hardware and on the problem being considered.

An interesting problem in the single-node pipe section representation is the use of a donor-cell approximation in the energy equation. To increase performance by reducing nodalization error, two alternatives are: (a) finite nodalization through use of a multinode pipe element, or (b) infinite nodalization, that is, going to the limit. The second alternative is examined.

The physical system under study is a single-phase incompressible flow through a pipe section with the assumption of a uniform heat transfer profile. A mathematical model is developed using mass, momentum, and energy balances. Infinite nodalization gives rise to a variable time delay. In two versions of this model the parity concept is not fully preserved. In addition, it is probably not as self-correcting as the original parity element. A simple model cannot handle some cases, while the energy equations in a full model degenerate into standard analog computer form. Finite memory size sets a limit on time delay size, and difference terms may limit accuracy.

Extension to full single-phase compressible is possible but requires the velocity field $v(x, t)$. The extension for the original single-phase compressible pipe element is, however, possible since inlet and outlet branches are assumed incompressible.

In conclusion, using infinite nodalization the parity concept is not fully preserved, the fraction of auxiliary computations increases, and difference terms may limit accuracy. Limited extension to single-phase compressible flow is possible.

\section{PLANS FOR THE COMING YEAR}

This project will not continue beyond the current year. Future needs relate to potential extension and development but not advanced research. Any development activities should be supported by other sponsors. 


\section{REFERENCES}

1. E.V. Depiante and J.E. Meyer. "Parity Simulation of Single-Phase Thermal Hydraulics." Nucl. Sci. Eng., forthcoming, 1989. (Att. 23)

2. E.V. Depiante and J.E. Meyer. "Two-Phase Thermal Hydraulic Analysis Using Parity Simulation." Nucl. Sci. Eng., forthcoming, 1989. (Alt. 24)

\section{RECENT PUBLICATIONS}

E.V. Depiante. "Parity Simulation of Single-Phase Thermal Hydraulics." Nucl. Sci. Eng., forthcoming, 1989. (Att. 23)

E.V. Depiante. "Two-Phase Thermal Hydraulic Analysis Using Parity Simulation." Nucl. Sci. Eng., forthcoming, 1989. (Att. 24)

P.J. Laughton. "Parity Simulation Applied to Reactor Physics Nodal Theory Transient Analysis." Proceedings of 15th Annual Nuclear Simulation Symposium, Canadian Nuclear Society, May 1989. (Att. 25) 
FRACTURE MECHANICS 


\section{FUNDAMENTALS OF ELASTIC-PLASTIC FRACTURE: THREE-DIMENSIONAL AND MECHANISTIC MODELLING}

\section{PERSONNEL}

Faculty:

Research Staff:

Collaborator:
D.M. P.arks, Department of Mechanical Engineering

F.A. McClintock, Department of Mechanical Engineering

Y. Wang, Department of Mechanical Engineering

H. Lee, Department of Mechanical Engineering

Y. Kim, Department of Mechanical Engineering

T. Nakamura, SUNY at Stony Brook

\section{ABSTRACT}

Detailed elastic-plastic finite element analyses of engineering crack configurations are providing deeper understanding of three-dimensional crack front stress and deformation fields. The calculations aid in establishing parametric limits of applicability for dominant singularity and local approaches to fracture analysis in ductile structures. Simplified (but highly accurate) models for analysis of cracked structures are being developed and enhanced. The serious consequences of even infrequent low toughness cleavage fracture transition in a normally ductile component (as has been observed in experiments at INEL) motivate mechanistic, statistical, and experimental investigation of this phenomenon.

\section{GQALS}

We seek to accurately predict fracture in surface-cracked pressure vessels and piping (plates or shells), especially under plastic overloads as in accidents or earthquakes. This may involve through-cracking followed by lateral growth. For practical reasons, the modeling is being done down to the millimeter scale, which is the roughness of macroscopic cracks, rather than at the $0.01 \mathrm{~mm}$ scale of the void growth or cleavage facets.

\section{PRQGRESS}

Detailed finite element analysis of surface-cracked plates. Parks and Wang (1) analyzed crack front fields in surface-cracked plate geometries subject to tensile loads ranging from small scale yielding through fully plastic conditions. Local crack front singularity amplitude (J) was evaluated. Detailed analysis of the near crack front stress revealed parametric regions of dominance of this singularity. Calculated surface displacements are in excellent agreement with Moire measurements made at INEL. The experimental/computational comparisons and the more comprehensive understanding of elastic-plastic surface-crack fields that this joint study has provided are highlighted in the joint MIT/INEL manuscript by Wang et al. (2).

Detailed finite element analysis of through-cracked plates. Most fracture analyses of through-cracked plates adopt two-dimensional idealizations of plane stress or plane strain. In plates of sufficiently small thickness $(t)$ compared to in-plane dimensions, Nakamura and Parks $(3,4,5,6)$ have performed several "universal" three-dimensional analyses of the near crack front regime. Loads transmitted to the crack from the periphery of the disk were characterized by plane stress dominant singular fields. Nakamura and Parks (3) considered Mode I elastic loading 
and carefully revealed the symmetric corner fields at the free surface intersection. For antisymmetric Mode II loading Nakamura and Parks (5) obtained the mixed Mode II and Mode III crack front singularities and the highly singular anti-symmetrical elastic corner singularities. They also noted that recent mixed-mode ductile fracture experiments in Japan indicated that, with any Mode II loading present, the first observed cracking occurred as "shear emanations" near these highly singular corner regions. Finally, Nakamura and Parks (4 and 6) solved the growth of crack front plastic zone in a thin plate from local plane strain plastic zones $\left(r_{p} / t<1\right)$ to "plane stress" plastic zones $\left(r_{p} / t>1\right)$. Only a gradual loss of local plane strain constraint and dominant singular fields was observed along the crack front as the plastic zone grew to many multiples of plate thickness. This suggests, as do certain fracture toughness experiments on specimens of substandard thickness, that elementary two dimensional models of crack tip "plane stress" plastic flow greatly overestimate the loss of local triaxial stress.

Davelopment of simplified models of surface cracks. Power law deformation theory plasticity 3 intitions of a deeply cracked body containing a ligament subject to combined tension and bending provide a basis for highly accurate line-spring models of fracture initiation from fatigine cracks (7). Deformation theory models are inappropriate for analysis of extensive through-thickness growth (as observed in INEL tests), so earlier flow theory plasticity lire spring models are being enhanced by staff member $H$. Lee in three important ways. First, a.. effective crack length formulation has improved the compliance and J estimation in the moderate- to large-scale yielding regime. Improved models of structural work hardening in the fully plastic ligament regime have been developed. Finally, incremental formulations which admit crack extension, as coupled to incremental spring kinematics, are being implemented.

Transition to cleavage in A710 steel at unexpectedly high temperatures. Further work with Dr. Reuter of INEL has shown that the transitions to cleavage observed from growing, slant-mode, through-cracks occur rather randomly, as if following a Poisson distribution, and may or may not show cleavage islands ranging from a few grain sizes to the specimen thickness. The ASME Boiler and I'ressure Vessel Code allows service at temperatures based on the least of a sample of three Charpy specimens, which turns out not to predict the cleavage transitions that occurred here. Extreme-value statistics are currently based on a given volume such as the initial plastic zone size and do not predict the cleavage islands that occur. Strip models that are 1- and 2-grain sizes wide are being proposed to model approximately the statistics of islands and crack growth before cleavage.

Relations between Charpy work, thickening, and crack-tip opening displacement (CVW, CVT, CVTOD). Bounds or estimates to these quantities can be obtained for power-law as well as non-hardening materials; little conceptual work but considerable routine effort would be required for 3-D finite element analysis. On the other hand, the limited value of the Charpy test for predicting cleavage transitions in structures may mean that, for practical purposes, the most appropriate approach would be to plot existing experimental data in terms of normalized parameters corresponding to power-law materials.

3-D planar elastic crack growth. A pattern of 3-D, Mode I cracked elements based on the 2-D elements developed for comminution has been found for modeling the fatigue crack growth stage in surface-cracked structures. Before development, it should be compared with the Cleary-Keat boundary element or node-release formulations.

2-D plastic crack growth. Literature studies of the underlying singularities show the asymptotic solutions ( 8 and possibly 9) to dominate in an impractically small region (10). No crack tip element has been found that would extend to the apparent rigid, linear-hardening plastic singularity of Kardomateas (11), with which any element should be consistent. There is a need for elements accommodating localization in regions near a crack-tip element $(12,13)$. 
Experiments on high-triaxiality and slant mode growth in medium specimens. Pending work at INEL, specimens for preliminary tests have been designed and are being made to explore cleavage transition from slant mode and high triaxiality pre-cracks. In accordance with INEL suggestions, Moiré patterns will be used for overall strain analysis; and if cleavage occurs, some tests will be made at INEL to allow acoustic emission studies of isolated early cleavage events.

Extreme-value statistical models of cleavage micromechanics. Recent workers in the literature have modeled statistical aspects of cleavage fracture toughness in terms of Weibull extreme-value statistics of potential cleavage nuclei within the crack tip plastic zone. The stress analyses upon which these studies are based are, for the most part, approximate plane strain idealizations, intended mainly for dimensional analysis. Staff member $Y$. Wang has quantitatively generalized these approaches to account for important three-dimensional aspects of the problem, including gradients in crack front singularity strength. Near transition temperature, the existence of patchy cleavage (see above) calls extreme-value statistics into question; but whatever the appropriate statistical models turn out to be, they will surely depend sensitively on the actual three dimensional elastic-plastic stress fields in the very near tip region. The detailed three-dimensional finite element solutions are being extensively processed for "global" aspects of crack tip plastic stress fields, including loss of asymptotic dominance.

Cracking in plastically heterogeneous media. The metallurgical heterogeneities of composition, micro structure, strength, residual stress, and toughness that are associated with structural weldments have largely precluded detailed local analysis of crack tip regions.

Recent experimental work at INEL on diffusion-bonded titanium/titanium alloy specimens has provided a model of cracking in regions of sharp strength differences. We have begun detailed finite element analysis of these specimens, bearing in mind recent developments for this class of problems by Shih and Asaro (14) and by Parks and Zywicz (15).

\section{PLANS FOR THE COMING YEAR}

- The detailed elastic plastic finite element studies of surface cracked plates will be completed, with emphasis on the practical case of stationary shallow surface cracks, including especially effects of front surface plastic flow, load biaxiality, and crack aspect ratio on asymptotic HRR dominance.

- The enhancements to the flow theory line-spring will be completed. Effective crack length and fully plastic hardening modifications are currently implemented and await only parametric studies. A framework for accommodating crack extension is in hand, awaiting implementation and development. Comparison with INEL's experimental observations of stable through-thickness cracking will be made.

- Post-processing or stationary three-dimensional crack front stress fields for weakest link (and other) statistical models of cleavage will continue.

- Three-dimensional finite element studies of the INEL diffusion bonded titanium specimens will be performed and critically compared with experiment.

- For 2-D plastic crack growth elements, we will explore steady flow numerically for comparison with the Kardomateas singularity.

- Experiments will be performed on high-triaxiality and slant-mode growth in mediumsized specimens, including preliminary Moiré studies, in accordance with INEL suggestions. 


\section{REFERENCES}

1. D.M. Parks and Y. Wang. "Elastic-Plastic Analysis of Part-Through Surface Cracks." In Analytical, Numerical, and Experimental Aspects of Three-Dimensional Fracture Processes, eds. A.J. Rosakis et al., ASME AMD-91, ASME, New York, New York, 1988, pp. 19-32. (Att. 32)

2. Y. Wang, D.M. Parks, W.R., Lloyd, W.G. Reuter, and J. Epstein. "Elastic-Plastic Deformation in Surface-Cracked Plates: Experiment and Numerical Analysis." Submitted to ASME Journal of Applied Mechanics, 1989. (Att. 34)

3. T. Nakamura and D.M. Parks. "Three Dimensional Stress Field Near the Crack Front of a Thin Elastic Plate." ASME Journal of Applied Mechanics, v. 55, 1988, pp. 805-813. (Att. 30)

4. T. Nakarnura and D.M. Parks. "Conditions for J-Dominance in Three-Dimensional Thin Cracked Plates." In Analytical, Numerical, and Experimental Aspects of ThreeDimensional Fracture Processes, eds. A.J. Rosakis et al., ASME AMD-91, ASME, New York, New York, 1988, pp. 227-238. (Att. 28)

5. T. Nakamura and D.M. Parks. "Anti-symmetrical 3D Stress Field Near the Crack Front of a Thin Elastic Plate." International Journal of Solids and Structures, forthcoming, 1989. (Att. 27)

6. T. Nakamura and D.M. Parks. "Three-Dimensional Crack Front Fields in a Thin Ductile Plate." Submitted to the Journal of the Mechanics and Physics of Solids, 1989. (Att. 29)

7. T. Shawki, T. Nakamura, and D.M. Parks. "Line-Spring Analysis of Surface Flawed Plates and Shells Using Deformation Theory." International Journal of Fracture, forthcoming, 1989. (Att. 33)

8. P. Ponte Castañeda. "Asymptotic Fields in Steady Crack Growth with Linear StrainHardening." J. Mech. Phys. Solids, v. 35, 1987, pp. 227-268. (Att. 38)

9. W.J. Drugan and X.Y. Chen. "Plane-Strain Elastic-Ideally Plastic Crack Fields for Mode I Quasistatic Growth at Large Scale Yielding- I. A New Family of Analytical Solutions." J. Mech Phys. Solids, v. 37, 1989, pp. 1-26. (Att. 39)

10. P. Gudmundson. "Validity of Asymptotic Crack Tip Solutions for Plastic Materials." Advances in Fracture Research, Proc. of the 7th Int. Conf. on Fracture, 1989, v. 1, pp. 315322. (Att. 40)

11. G.A. Kardomateas. Mixed Mode I and II Fully Plastic Crack Growth from Simulated Weld Defects. Ph.D. thesis, MIT Department of Mechanical Engineering, 1985, Chap. 6. (Att. 41)

12. M. Ortiz, Y. Leory, and A. Needleman. "A Finite Element Method for Localized Failure Analysis." Comp. Meth. Appl. Mech. Engrg., v. 61, 1987, pp. 189-214. (Att. 42)

13. T. Belytschko, J. Fish, and B.E. Engelmarın. "A Finite Element with Embedded Localization Zones." Comp. Meth. Appl. Mech. Engrg., v. 70, 1988, pp. 59-89. (Att. 43) 
14. C.F. Shih and R.J. Asaro. "Elastic-Plastic Analy'sis of Cracks on Bimaterial Interfaces: Part I-Small Scale Yielding." Journal of Applied Mechanics, v. 55, 1988, pp. 299-316. (Att. 45)

15. D.M. Parks and E. Zywicz. "Elastic/Perfectly-Plastic Small Scale Yielding at BiMaterial Interfaces." Advances in Fracture Research, eds. K. Salama et al, Pergamon Press, Oxford, v. 4, 1989, pp. 3081-3088. (Att. 46)

\section{RECENT PUBLICATIONS}

F.A. McClintock. "Reduced Crack Growth Ductility Due to Asymmetric Configurations." Presented at the IUTAM Symposium, "Recent Advances in Nonlinear Fracture Mechanics." California Institute of Technology, March 14-16, 1988. International Journal of Fracture, forthcoming, 1989. (Att. 26)

T. Nakamura and D.M. Parks. "Anti-symmetrical 3D Stress Field Near the Crack Front of a Thin Elastic Plate." International Journal of Solids and Structures, forthcoming, 1989. (Att. 27)

T. Nakarnura and D.M. Parks. "Conditions for J-Dominance in Three-Dimensional Thin Cracked Plates." In Analytical, Numerical, and Experimental Aspects of Three-Dimensional Fracture Processes, eds. A.J. Rosakis et al., ASME AMD-91, ASME, New York, New York, 1988, pp. 227-238. (Att. 28)

T. Nakamura and D.M. Parks. "Three-Dimensional Crack Front Fields in a Thin Ductile Plate." Submitted to the Joumal of the Mechanics and Physics of Solids, 1989. (Att. 29)

T. Nakamura and D.M. Parks. "Three Dimensional Stress Field Near the Crack Front of a Thin Elastic Plate." ASME Journal of Applied Mechanics, v. 55, 1988, pp. 805-813. (Att. 30)

D.M. Parks. "A Surface Crack Review: Elastic and Elastic-Plastic Behavior." ASTM Symposium on Surface Crack Growth, Sparks, Nevada, April 25, 1988. ASTM STP 1060, AST'M Philadelphia, forthcoming, 1989. (Att. 31)

D.M. Parks and $Y$. Wang. "Elastic-Plastic Anaiysis of Part-Through Surface Cracks." In Analytical, Numerical, and Experimental Aspects of Three-Dimensional Fracture Processes, eds. A.J. Rosakis et al., ASME AMD-91, ASME, New York, New York, 1988, pp. 19-32. (Att. 32)

T. Shawki, T. Nakamura, and D.M. Parks. "Line-Spring Analysis of Surface Flawed Plates and Shells Using Deformation Theory." International Jc arnal of Fracture, forthcoming, 1989. (Att. 33)

Y. Wang, D.M. Parks, W.R. Lloyd, W.G. Reuter, and J. Epstein. "Elastic-Plastic Deformation in Surface-Cracked Plates: Experiment and Numerical Analysis." Submitted to ASME Journal of Applied Mechanics, 1989. (Att. 34) 


\section{COMMINUTION OF ENERGY MATERIALS}

\section{PERSONNEL}
Faculty:
C.R. Peterson, Department of Mechanical Engineering
F.A. McClintock, Department of Mechanical Engineering
Research Staff:
J.R. Williams, Department of Civil Engineering
Graduate Students:
J.R. Easter, A.D. Kurfess

\section{ABSTRACI}

Comminution, the reduction of coarse material to fine particles, is a necessary step in the preparation of clean coal and the beneficiation of ores, perhaps including oil shale. As required product size decreases, conventional, notoriously low efficiency processes are increasingly unsatisfactory. This program seeks, through better understanding of the behavior of particle beds and the fracture of particles within such beds, to devise more effective fine particle crushing machines. A computer simulation of two-dimensional beds of spherical particles has been developed and is suitable for use as a design tool. Experimental work with large-particle, relatively homogeneous beds correlates well with simulator behavior. Experimental and artalytical work on individual particles has established appropriate particle failure criteria for brittle particles subject to multiple point loads as experienced within a bed. The failure of plastic particles under such loading is under continuing study. A novel crusher/material transport concept has evolved from these studies and will serve as the focal point for further studies and design work.

\section{GOALS}

The ultimate goal of this program is to design substantially more effective means to grind materials to very small sizes, perhaps as small as 10 microns. Useful quantity production of material of that size prohibits attack of individual particles-hence the interest in large masses of particles in the form of particle beds. The research goal of the program, then, is to gain an understanding of the behavior of particle beds, including the mechanisms that lead to the fracture of individual particles within the bed. It will also be necessary to study the movement of particles within the bed, including the relative motion of various size particles, in order to effectively discharge finished material. Such an understanding, even if only qualitative, is leading to the design of geometries and machine actions that should substantially improve today's performance.

\section{PROCRESS}

In work previously reported, computer simulations seem to reasonably describe the behavior of a two-dimensional bed of spherical particles, including the failure of particles as loads increase. However, an appropriate failure criterion for spheres subjected to multiple loads from neighboring particles was not known. Simulations tried four different failure criteria, yielding results that differed significantly for otherwise identical beds and loading. It was necessary, then, to determine appropriate failure criteria for spherical particles subject to multiple point loads. Previous work in this program, and in many others, explored only failure under two-point loading between flat plates. 
It is understood that excessive fine material will "blunt" crushing action by dividing applied loads among many small contact forces. In addition, however, it was suggested that many such loads would create a compressive stress within any particle that might inhibit fracture. The "hydrostatic effect" would be of practical consequence since, while blunting might be overcome by increasing the applied load, such fracture inhibition could not be so overcome. Thus, this portion of the program was also directed specifically to searching for any such detrimental hydrostatic effect.

Both experimental and analytical projects were undertaken.

The experimental project (1) determined the fracture behavior of both brittle (glass) and plastic (acrylic) spheres. One-inch spheres were subjected to the usual two-point loading between flat plates and to such primary loading plus secondary loads on the "equator" of the sphere at right angles to the primary loading. Equatorial loads up to $30 \%$ of the primary load had no appreciable effect on the primary load necessary to cause fracture. It had been thought that, upon loading, cracks would propagate stably to deep within the sphere before becoming unstable. In that case, small side loads would easily offset tensile stresses created by the primary load, equatorial loads being the most effective in inhibiting deep crack growth. Experimental evidence, however, suggests that the transition to unstable behavior occurs very near the surface at the primary load point, where side loads have very little influence. An approximate calculation of the stress distribution due to a set of point loads confirms their negligible effect in regions close to the primary load point (2), as follows. An exact solution to the elasticity problem exists, but its form is too cumbersome for present purposes. In previous work on this program, Ding (3) showed that the stress distribution for a point load on a semiinfinite body is a good approximation to that exact solution for a sphere. This approximate solution was used in a computer program to find principal stresses along the radial line of action of the primary load arising from a collection of radial point loads at other locations on the surface. These calculations indicate that equatorial loads, even if equal to the primary load, have little influence in the region just beneath the primary load where unstable fracture is initiated. Furthermore, for a location just below the primary load, the stress contribution from nearby loads of equal magnitude is small. These analyses all ignore the wedging action of the crushed zone immediately beneath the applied load which, in the nearby region, would certainly overcome compressive contributions from distant side loads. Thus the (size dependent) maximum force failure criterion, the simplest of those tried in the bed simulation work, is an appropriate failure criterion.

Though side loads have no strengthening effect with brittle particles, it is believed that they will influence the behavior of plastic materials. Plastic behavior beromes important as applications demand finer grinding because, at small enough particle size, all materials behave plastically. Accordingly, similar multi-point loading tests were carried out on one-inch acrylic spheres. With side loads up to about $20 \%$ of the principal fracture load, there appears to be no significant effect of side loading. There was appreciable plastic deformation of the spheres before fracture, with fracture well defined by an audible snap and drop in load.

While side loads did not significantly affect brittle failure loads, they did affect the shape of fragments. Simple axial loading tended to produce cubic major fragments, while side loading tended to produce long splinter-like particles. If a glass sphere was unloaded just before fracture (after the creation of some crushing and local cracking), rotated slightly, and reloaded, it was sometimes possible to produce a hemisphere with very little reload force. 
Plastic spheres did not disintegrate upon fracture as glass spheres did. Instead, a roughly cylindrical, stump-like, load-bearing member remained between the load surfaces while segments broke away from the sides.

In conclusion, the simple, maximum load failure criterion seems appropriate for brittle spheres and for plastic spheres under modest side loading. Neither experimental evidence nor analytical results are available to suggest the performance of plastic spheres having side loads comparable to the major load.

In anticipation of the need for modeling deep cracks, an efficient 2-D model of brittle crack growth was developed. Although it now appears not needed for particle fracture, it will prove useful in other applications, such as planar fatigue crack growth. Such a model may be extended to the 3-D case. It is also hoped that experience with the model will suggest means for its extension of the problem of fully plastic crack growth. An element has been written to model Mode I elastic crack growth without node release or remeshing. The approach of Tong, Pian, and Lasry (4) was adapted to crack propagation. An assumed stress hybrid finite element is formed in which the stress terms, including the singular $\left(\mathrm{K}_{\mathfrak{l}}\right)$ term, are functions of a complex variable, and the hybrid energy functional is minimized with respect to prescribed boundary displacements. These displacements are interpolated from the nodal displacements using the linear or quadratic displacement distributions of conventional finite elements; thus, interelement displacement compatibility is enforced. An existing hybrid crack element with crack tip location an input parameter, originally written for the FEABL/EGL package of M.I.T.'s Aeroelastics and Structures Laboratory, has been modified for use with program ABAQUS. Conventional isoparametric elements surround the above special crack-containing hybrid element, which takes the place of two conventional elements along the path of Mode I crack advance. The special element is advanced only stepwise as the crack grows continuously.

Displacement boundary conditions corresponding to the $\mathrm{K}_{\mathrm{I}}$ elastic field for 6 crack tip positions were imposed on a 34-element semicircular mesh with 8 elements along its diameter (see Fig. 1). Tests were performed with the crack element in the central two of these locations, and as stepped ahead by a conventional element length $l$. Between $X_{t} / l=-0.2$ and 0.8 , the maximum error was $1.2 \%$. Stepping the hybrid element by $/$ when $X_{t} /$ lreached $0.8\left(\right.$ to $\left.X_{t} / l=-0.2\right)$ gave a change in $\mathrm{K}_{\mathrm{I}}$ of only $0.5 \%$.

\section{PLANS FOR THE COMING YEAR}

Although there are sorne details that must be resolved (e.g., fracture criteria for plastic spheres and fine particle accommodation and transport), the bed simulation is now sufficient to serve as a useful design tool. Hence the program will shift in spirit from one of preparation to one of directed research. A. new design concept, combining crushing and material transport characteristics that suggect a po.ential for high performance, will provide the focus for this new direction. The concept is an axially symmetric geometry that, by expanding radially, provides a constant (or even increasing) material through-flow area as the gap between opposing machine surfaces decreases. This provides for a reasonable discharge area even for small gaps, and it will also allow control of local fluid velocities to selectively move particles through the machine. 
Specific tasks for the coming year include:

- Preliminary design studies of the proposed concept, including, where necessary, simple physical modeling of material behavior.

- Upgrading of the bed simulation model to treat much larger numbers of particles and to include fluid transport of particles. Related work on fluidized bed behavior will be reviewed and incorporated as appropriate.

- $\quad$ Renewed bed experimental studies. Quantitative information is needed on bed behavior as a function of bed depth, particle size distribution, and a variety of ideas to enhance efficiency for realistic design work. It will also be necessary to compare the behavior of spherical and granular particle beds. It is hoped that these studies can include acoustic measurements in conjunction with INEL personnel.

- Various projects to close out prior studies. These include further experimental testing of the sphere fracture analyses (particularly for plastic spheres), higher laterai loads, and, perhaps, analyses of plastic sphere behavior. Depending upon level of support, the study of plastic failure can be expanded since this behavior will ultimately limit performance for very small particles of any material.

\section{REFERENCES}

(1) A.D. Kurfess. Fracture Criteria for Brittle and Plastic Spheres. M.S. thesis, MIT Department of Mechanical Engineering, May 1989. (Request copy if needed.)

(2) J. Easter. "Calculation of Stresses from a Set of Point Loads on the Surface of an Elastic Sphere." Research Memorandum No. 272, Fatigue and Plasticity Laboratory, MIT, August 14, 1989. (Att. 35)

Z.R. Ding. Effect of Contact Force Patterns on Particles in a Bed. M.S. thesis, MIT Department of Mechanical Engineering, June 1987. (Request copy if needed.)

(4) P. Tong, T.H.H. Pian, and S.J. Lasry. "A Hybrid Element Approach to Crack Problems in Plane Elasticity." Intermational J. for Numerical Methods in Engineering, v. 7, 1973, pp. 297-308. (Att. 44)

\section{RECENT PUBLICATIONS}

J.R. Easter. "Calculation of Stresses from a Set of Point Loads on the Surface of an Elastic Sphere." Research Memorandum No. 272, Fatigue and Plasticity Laboratory, MIT, August 14, 1989. (Att. 35)

J.R. Easter. A Finite Element for Crack Growth with a Tip Position Parameter. M.S. thesis, MIT Department of Mechanical Engineering, May 1989. (Request copy if needed.)

A.D. Kurfess. Fraciure Criterion for Brittle and Plastic Spheres. M.S. thesis MIT Department of Mechanical Engineering, May 1989. (Request copy if needed.) 


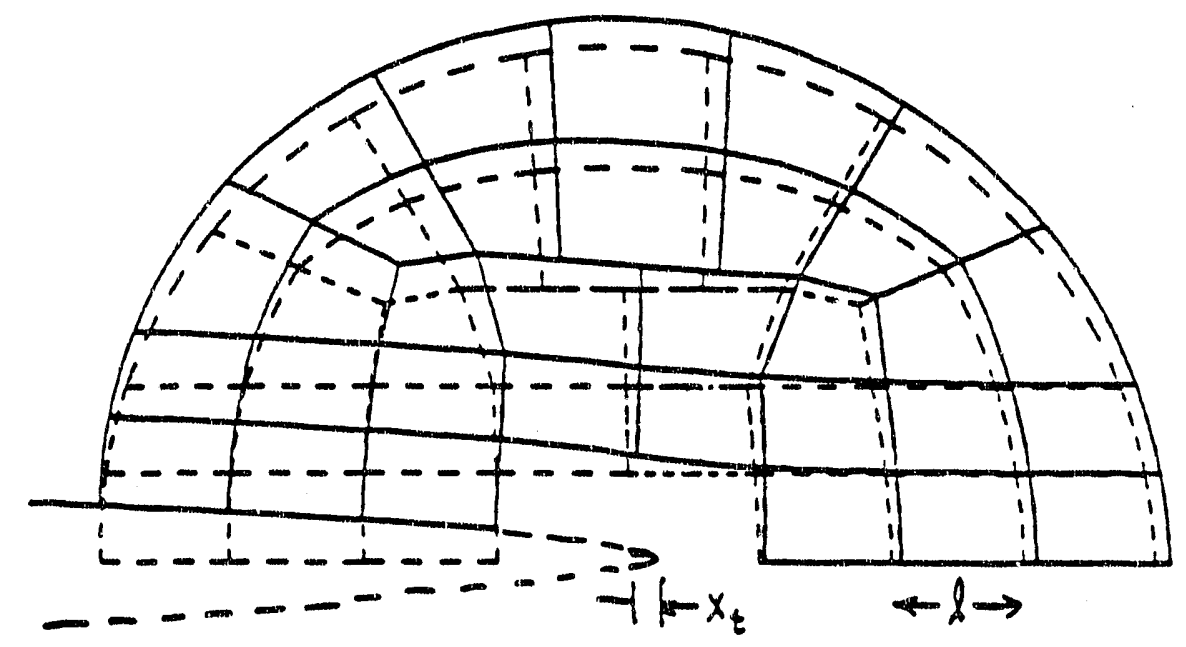

$\begin{array}{lllllll}x_{t} / 2 & -0.8 & -0.5 & -0.2 & 0.2 & 0.5 & 0.8\end{array}$

$\begin{array}{lllllll}K_{I} & 1.029 & 1.025 & 0.994 & 0.999 & 1.010 & 0.988\end{array}$

KII Identically zero

Figure 1. Hybrid crack element (Pian). 
7
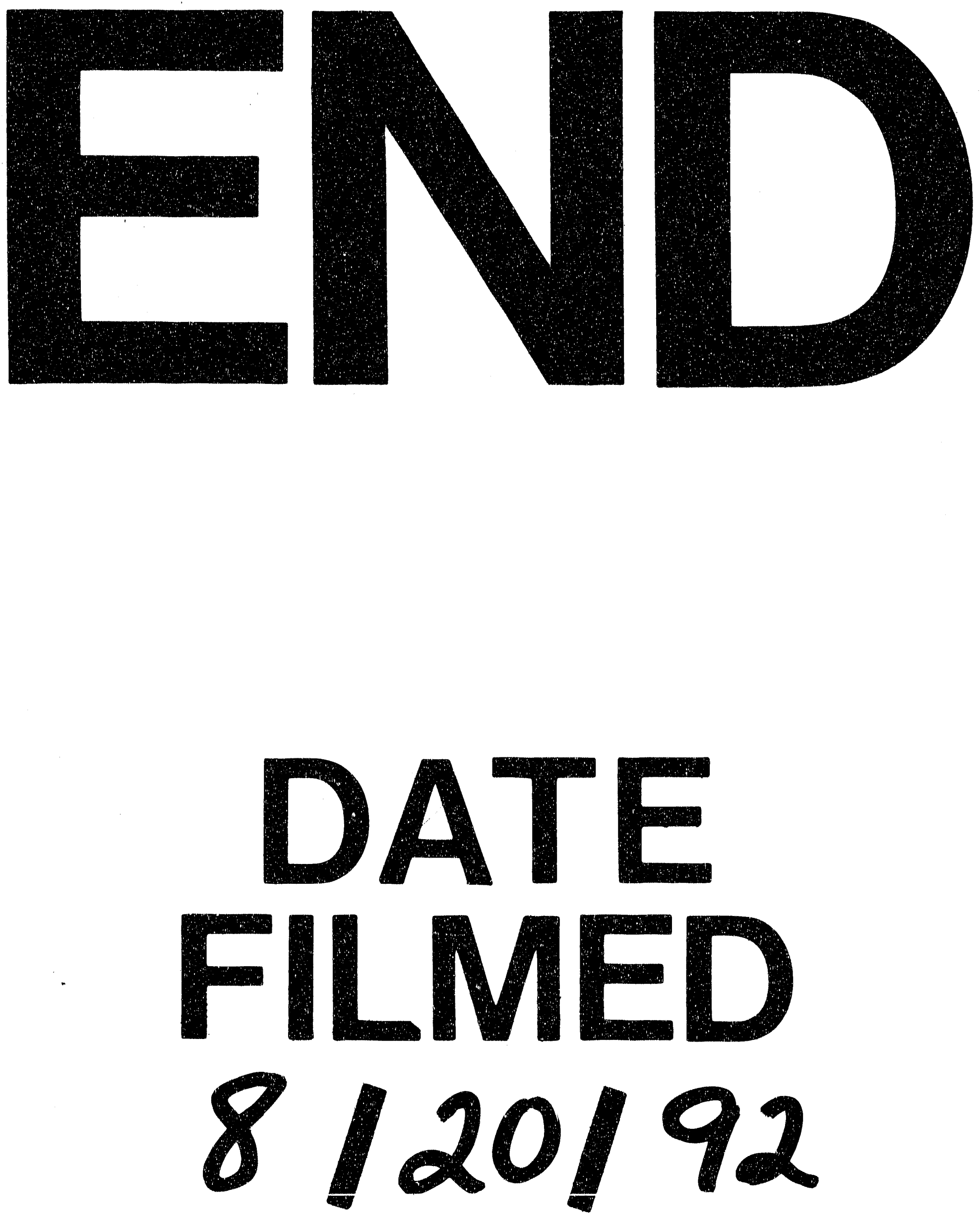

刋 
